\title{
Spectrometric Study of the Nitrile-Ketenimine Tautomerism
}

\author{
Hebe Saraví Cisneros, Sergio Laurella, Danila L. Ruiz, Agustín Ponzinibbio, \\ Patricia E. Allegretti, and Jorge J. P. Furlong
}

LADECOR (UNLP), División Química Orgánica, Departamento de Química, Facultad de Ciencias Exactas, Universidad Nacional de La Plata, Calle 47 y 115, 1900 La Plata, Argentina

Correspondence should be addressed to Jorge J. P. Furlong, furlong@quimica.unlp.edu.ar

Received 13 October 2008; Revised 17 February 2009; Accepted 8 June 2009

Recommended by Craig J. Eckhardt

\begin{abstract}
Mass spectrometry is used to evaluate the occurrence of the nitrile-ketenimine tautomerism. Mass spectra of two differently substituted nitriles, ethyl-4,4-dicyano-3-methyl-3-butenoate and diethyl-2-cyano-3-methyl-2-pentenodiate are examined looking for common mass spectral behaviors. Ion fragmentation assignments for specific tautomers allow to predict the presence of the corresponding structures. Additionally, the mass spectrum and nuclear magnetic resonance spectra of ethyl-4,4-dicyano2,2-diethyl-3-methyl-3-butenoate and that of the corresponding amination product support the occurrence of the ketenimine tautomer in the equilibrium.
\end{abstract}

Copyright (c) 2009 Hebe Saraví Cisneros et al. This is an open access article distributed under the Creative Commons Attribution License, which permits unrestricted use, distribution, and reproduction in any medium, provided the original work is properly cited.

\section{Introduction}

Few reports have been found on the occurrence of nitriles in equilibrium with the corresponding tautomers, the ketenimines. Some studies where enolization of nitriles takes place have been found [1-3]. Among these tautomeric compounds the most interesting ones were those which involve a methylene hydrogen $\gamma$ to the nitrile group and electron-acceptor groups as-CN or-COOR (Scheme 1) [3].

The majority of nitriles appear to favour strongly the cyano form in this equilibrium [1]. Kasturi et al. [2] have carried out the study of the UV absorption spectra of several 1,2dicyano esters and 1,1,2-tricyano compounds with a view to demonstrate the presence of nitrile-ketenimine tautomerism. They have synthesized several condensation products of $\beta$-ketoesters with malononitrile and ethyl-cyanoacetate in connection with the synthesis of heterocyclic compounds. From the analysis of the UV spectra in ethanol and in ethanol/sodium hydroxide solution there was observed a hyperchromic effect on the band around $355 \mathrm{~nm}$ (detectable only in polar hydroxylic solvents) that could be assigned to the presence of the ketenimine structure [3].

Contrarily, the long wavelength UV absorption band present in the spectra of some alkylidene malononitriles and cyanoacetates has been claimed to be a consequence of anion formation and not of nitrile-ketenimine tautomerism [4].

Additionally, in the IR spectra of these compounds, absorption bands between 2100 and $1500 \mathrm{~cm}^{-1}$ which could be expected if any ketenimine had been present were not observed [5].

A highly enantioselective direct dialkyl allylic electrophilic functionalization by addition of diethyl azodicarboxylates to alkylidene cyanoacetates and malononitriles (commercially available organocatalysts) has been demonstrated, and can be applied to other electrophilic addition reactions [6].

Tautomerism studies are notoriously relevant in various biologically important systems, and spectrometric methods, mainly NMR, have been used [7-22].

Mass spectrometry has already demonstrated to be useful for the study of prototropic tautomerism (keto-enol, amideimidol, amine-imine, etc. [23-49]). Some of those processes are really difficult to be studied by the NMR, where the solvent plays a key role. Many times interesting tautomeric structures are not detected by this technique which might be not the case of mass spectrometry since tautomerism occurs in the gas phase previous to ionization. This is why this methodology has been chosen to study the nitrileketenimine equilibrium trying to find experimental evidence 


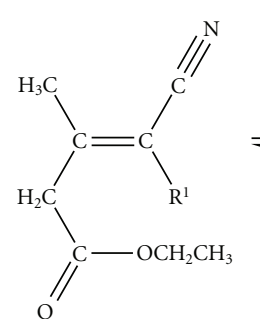

Nitrile

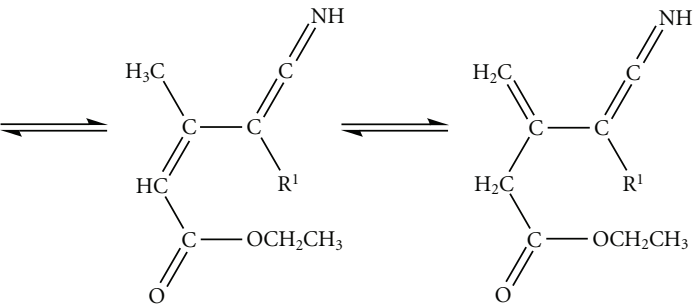

Ketenimines

R: $\mathrm{CN}$ or $\mathrm{COOCH}_{2} \mathrm{CH}_{3}$

Scheme 1: Nitrile-ketenimines equilibria.

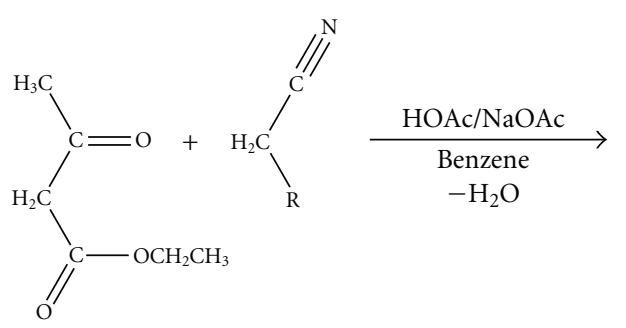

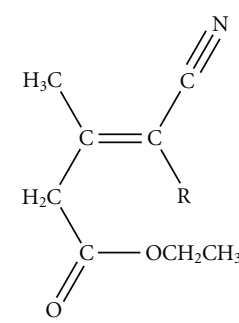

(E or Z)

Scheme 2: Synthesis of the selected nitriles.

about the occurrence of the ketenimine tautomer through the interpretation of mass spectral peaks of selected nitriles.

In order to get further support for the occurrence of the ketenimine tautomeric form, it has been resourced to additional experimental evidence as it is the case of an electrophilic addition reaction that can only take place through an specific tautomer (ketenimine). Amination was selected and although a mechanistic study of amination of ketenimines is lacking, it is known that amination of ketenimines forms amidines. By high-level ab-initio calculations Sung et al. [50] concluded that amination of ketenimines proceeds via amine addition across the $\mathrm{C}=\mathrm{N}$ bond rather than the $\mathrm{C}=\mathrm{C}$ bond, followed by tautomerization to form the amidine product. They have observed an intermediate vinylidendiamine by low-temperature proton NMR spectrometry.

The main purpose of the present work is to find experimental evidences for the occurrence of the ketenimine structure in equilibrium with the nitrile tautomer.

\section{Experimental Part}

2.1. Synthesis of Nitriles and Amidine. The ethyl esters of the alkylidene malononitrile and the alkylidene cyanoacetate, ethyl-4,4-dicyano-3-methyl-3-butenoate and diethyl2-cyano-3-methyl-2-pentenodiate, were synthesized according to the condensation procedure of Cope-Knoevenagel $[51,52]$ (Scheme 2).

The ethyl-4,4-dicyano-2,2-diethyl-3-methyl-3-butenoate was synthesized according to literature procedures [53].

The synthesis of the corresponding amidine (prepared by reaction with diethylamine) was carried out according to the general preparation procedure [52], and it was recrystallized up to constant melting point $\left(163-164^{\circ} \mathrm{C}\right)$.

\subsection{Structural Determinations}

2.2.1. Gas Chromatography-Mass Spectrometry-Single Quadrupole. These determinations were performed by injection of methanol solutions $(1 \mu \mathrm{L}, 100 \mu \mathrm{g} / \mathrm{mL}$ aprox.) in an HP 5890 Chromatograph coupled to an HP 5972 A mass selective detector (unit mass resolution). An HP5-MS capillary column $(30 \mathrm{~m} \times 0.25 \mathrm{~mm} \times 5 \mu \mathrm{m})$ has been used with Helium as the carrier gas $(0.6 \mathrm{~mL} / \mathrm{min}$ in column, split ratio $1: 30$ ). The temperatures set points were $200^{\circ} \mathrm{C}$ in the split injector, $300^{\circ} \mathrm{C}$ in the interface, $185^{\circ} \mathrm{C}$ in the ion source and the oven ramp started at $40^{\circ} \mathrm{C}(5$ minutes $)$, and ended at $290^{\circ} \mathrm{C}$ with a heat rate of $20^{\circ} \mathrm{C} / \mathrm{min}$. The electron energy was $70 \mathrm{eV}$, and the pressure in the mass spectrometer was lower than $10^{-5}$ torr, thus precluding ion molecule reactions.

Isotopic exchange was performed by dissolution of the corresponding compound in methanol- $\mathrm{d}_{1}$. Mass spectra were analyzed one hour after dissolution.

The relevance of spectrometric data as a predictive tool in regard to tautomeric equilibria depends mainly on the fact that the contribution due to tautomerization of molecular ions in the gas phase does not take place or can be ignored. The importance of this point comes from the physicochemical properties of ionic and radical species, quite different from the neutral ones. This could be the reason of possible distortion of results and loss of the desirable predictive power of the methodology.

It has been demonstrated, in the case of keto-enol tautomerism of a variety of carbonyl and thiocarbonyl 
compounds [38-49], that there is no significant interconversion of the tautomeric forms in the gas phase following electron impact ionization in the mass spectrometer (molecular ions, $\mathrm{M}^{+}$, do not seem to undergo unimolecular tautomerization), and, even more surprising, for GC/MS experiments, once the solvent is separated after injection in the injection port of the gas chromatograph, tautomerism mechanisms (intermolecular, unimolecular) would not seem to take place even with no GC separation (under the selected experimental conditions). These conclusions are supported by temperature studies at the ion source (negligible effect) and at the injection port of the gas chromatograph with a shifting effect in agreement with the corresponding heats of tautomerization $[42,47]$. In fact, this process would take place very fast under the working conditions in the GC.

Separation of tautomers in the analytical column is frequently very difficult; consequently the different pathways of fragmentation of the tautomeric forms have to be used for identification of individual tautomers. For this reason and because of the high similarity between MS (commercial databases) and GC/MS spectra, analytical separation has not been considered critical for the present work. Analogously, it is thought that most of the conclusions could be useful to analyze spectra registered with mass spectrometers equipped with direct insertion probes.

2.2.2. Gas Chromatography-Mass Spectrometry-Ion Trap. These determinations were performed by injection of methanol solutions $(1 \mu \mathrm{L})$ in a Thermo Quest Trace 2000 coupled to Finnigan Polaris ion trap detector (unit mass resolution) under the same experimental conditions already mentioned for the single quadrupole GC/MS system. This instrumentation was utilized to confirm proposed fragmentation pathways by CID (collision induced dissociation) using Helium as the damping gas, a CID voltage of $4-7 \mathrm{eV}$ and an excitation energy of $0.3-0.45$ (values were optimized for each ion transition). These experiments were done by selecting a precursor ion from the full-scan spectrum and carrying out the corresponding MS/MS product ion scan.

2.2.3. Nuclear Magnetic Resonance. ${ }^{1} \mathrm{H}$ NMR spectra in $\mathrm{CDCl}_{3}$, were recorded with a Varian Mercury Plus spectrometer operating at $4.7 \mathrm{~T}$. The typical spectral conditions were as follows: spectral width $3201 \mathrm{~Hz}$, acquisition time 4.09 seconds and 16 scans per spectrum. Digital resolution was $0.39 \mathrm{~Hz}$ per point. Deuterium from the solvent was used as the lock and TMS as the internal standard. Sample concentration was $20 \mathrm{mg} / \mathrm{mL}$. Measurements were performed at $25^{\circ} \mathrm{C}$.

${ }^{13} \mathrm{C}$ proton decoupled and gated decoupled spectra were recorded with the same spectrometer from $\mathrm{CDCl}_{3}$ solutions at $25^{\circ} \mathrm{C}$. The spectral conditions were as follows: spectral width $10559 \mathrm{~Hz}$, acquisition times 1.303 seconds and 1000 scans per spectrum. Sample concentration was $40 \mathrm{mg} / \mathrm{mL}$, and digital resolution was $1.29 \mathrm{~Hz}$ per point.

A standard one-dimensional (1D) proton NMR spectrum and a carbon spectrum with broad-band proton decoupling were run of each sample, supplemented by

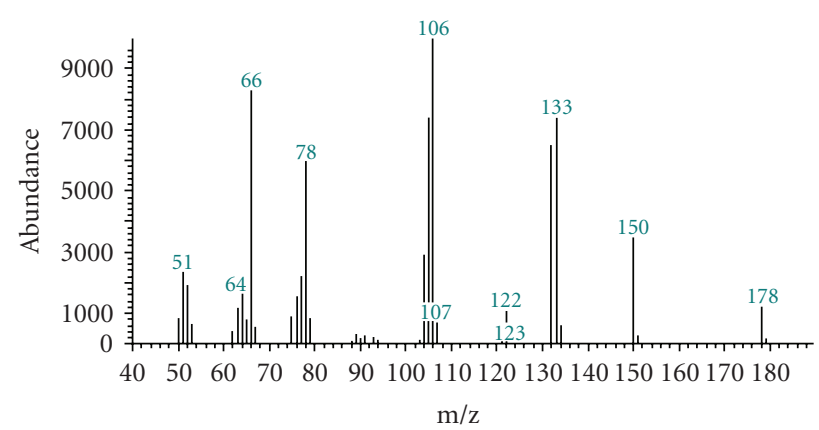

Figure 1: Mass spectrum of ethyl-4,4-dicyano-3-methyl-3butenoate.

2D gradient-selected COSY and multiplicity-edited HSQC experiments to helpwith the assignment of signals. All 2D spectra were recorded with the same spectrometer.

Vendor provided pulse sequences were used throughout the work.

2.3. Computational Procedure. Theoretical calculations offer an interesting approach to define relative stabilities of compounds that participate in different kinds of equilibria. That is why AM1 calculations [54] were performed on the ethyl-4,4-dicyano-3-methyl-3-butenoate using the standard Hyperchem package [55]. Since it has been resorted to heat of formation values in order to rationalize experimental findings and the AM1 technique has been specially parameterized to reproduce this sort of experimental data, the authors think that this choice is a sensible one for the molecular set under consideration. Besides, previous computations obtained for this kind of studies have given quite sensible results in order to correlate experimental and theoretical data, so that it is deemed that is not necessary to appeal to higher levels of molecular electronic structure sophistication.

\section{Results and Discussion}

The relative stabilities of all possible tautomers for the ethyl4,4-dicyano-3-methyl-3-butenoate have been estimated by semi-empirical calculations (AM1 level), and the results are shown in Table 1.

The predicted most likely tautomerization process involves the conversion of the nitrile-keto form I to the ketenimine-keto III. The energy barrier to form tautomers II, V and, VI indicates that they are likely to occur in some extent while tautomerism involving the methyl moiety (IV) and the double tautomerization process (VII and VIII) seem to be less likely.

The mass spectrum of ethyl-4,4-dicyano-3-methyl-3butenoate is shown in Figure 1.

From the assignment of the main fragment peaks it seems clear the occurrence of the ketenimine form because there exist fragment ions that can only be explained from that tautomer. The proposed fragmentation mechanisms are supported by the data although it should be noted that there is no absolute proof for them since there might be alternative pathways that are not eliminated by these experiments. 
TABLE 1: Heats of formation and relative stabilities of the tautomeric forms of ethyl-4,4-dicyano-3-methyl-3-butenoate by AM1 calculations.

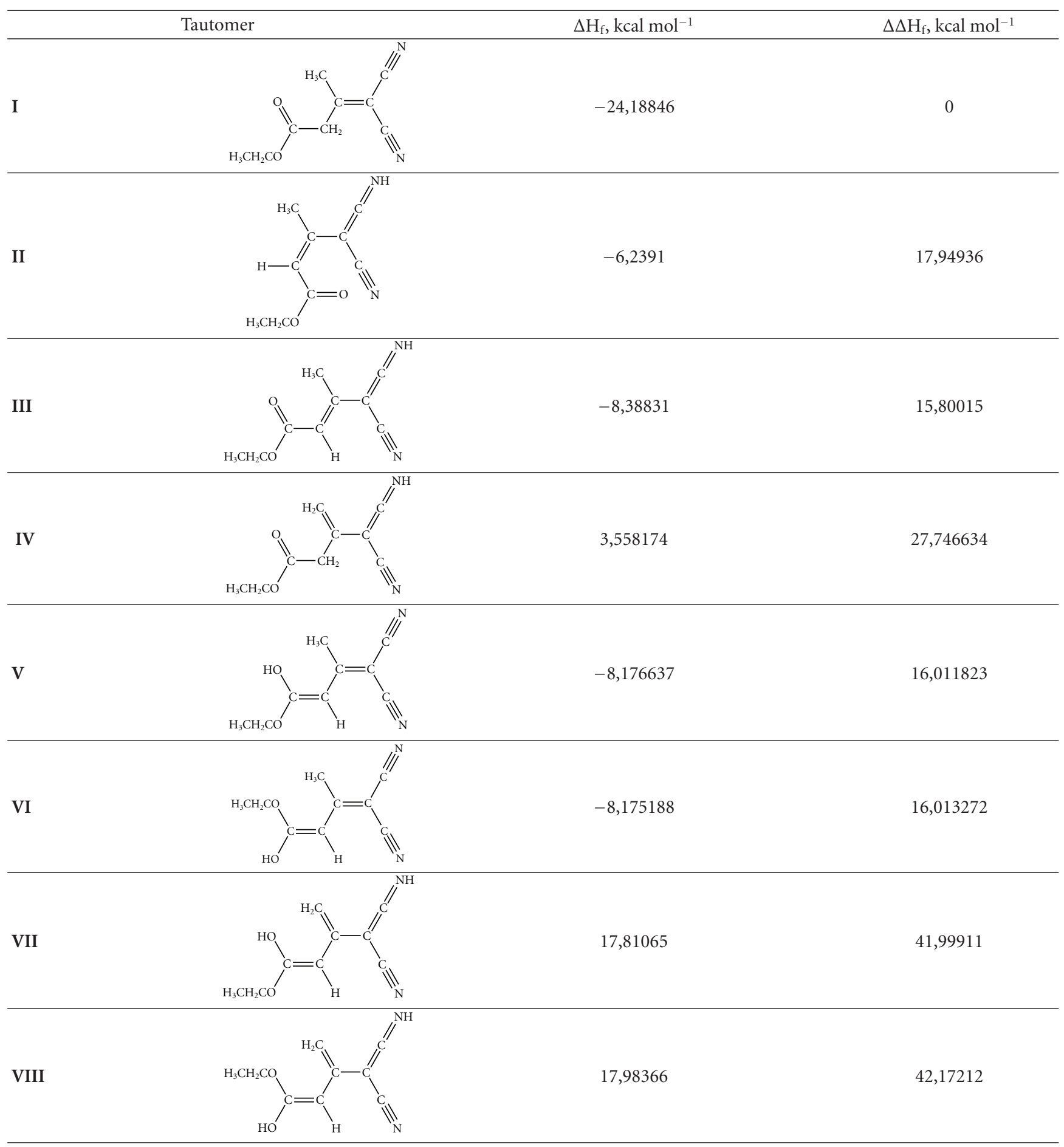

The peaks at $\mathrm{m} / \mathrm{z} 104,105,106,132,133$, and 150 can be justified from both tautomeric forms (Scheme 3 ).

The fragment ion at $\mathrm{m} / \mathrm{z} 66$ can only be justified from the ketenimine form (Scheme 4). The ion at $\mathrm{m} / \mathrm{z} 106$ can also be formed by the other ketenimine form (Scheme 3(b)) which can render the fragment ion at $\mathrm{m} / \mathrm{z} 66$ (Scheme 4(b)).

It seems that the fragment at $\mathrm{m} / \mathrm{z} 78$ could be assigned to the ketenimine since the only possible alternative to form this ion would come from that one at m/z 106 by loss of $\mathrm{HCNH}$ through hydrogen rearrangement.

In case that tautomerization involving the enol from the ester moiety occurs, there are no evident pathways for the formation of m/z 66 and the ions in the range m/z 104-106.

The fragmentation pathways were confirmed by GC/MSIon Trap experiments (Table 2): the ions at $\mathrm{m} / \mathrm{z} 66,132,133$, and 150 are generated from the molecular ion at $\mathrm{m} / \mathrm{z} 178$; the 


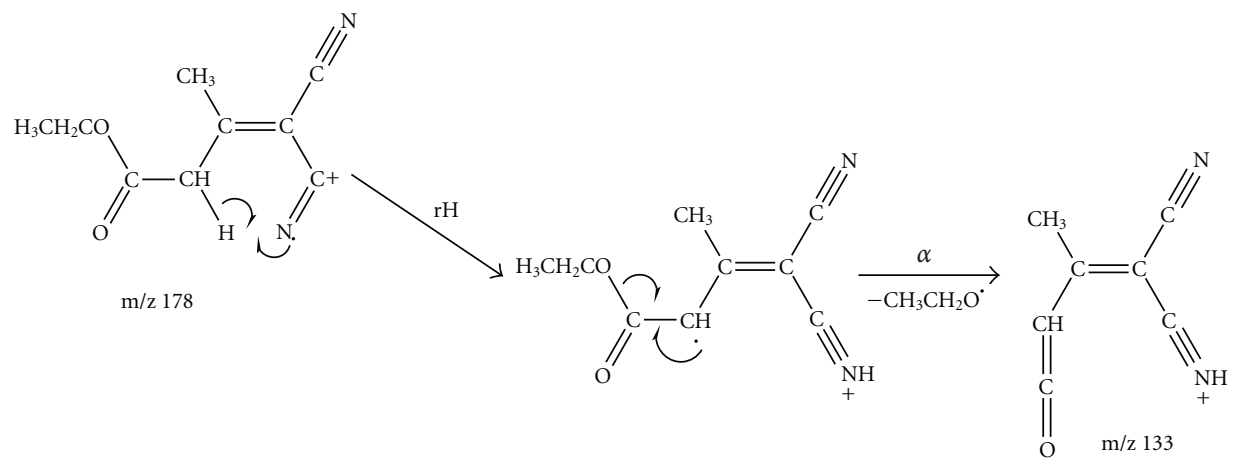<smiles>CC(C#N)=C(C#N)C#N</smiles>

* McLafferty's conventions are followed in all fragmentation schemes: half arrows indicate the movement of a single electron as observed for $\alpha$-cleavage mechanisms $(\alpha)$ and radical-site hydrogen rearrangements $(\mathrm{rH})$, full arrows are used for inductive cleavage mechanisms (i) indicating the transfer of an electron pair. The use of double arrows indicates the equilibrium between tautomers as neutral species in the gas phase. It does not intend to imply tautomerim between charged species.

(a)

Scheme 3: Continued. 

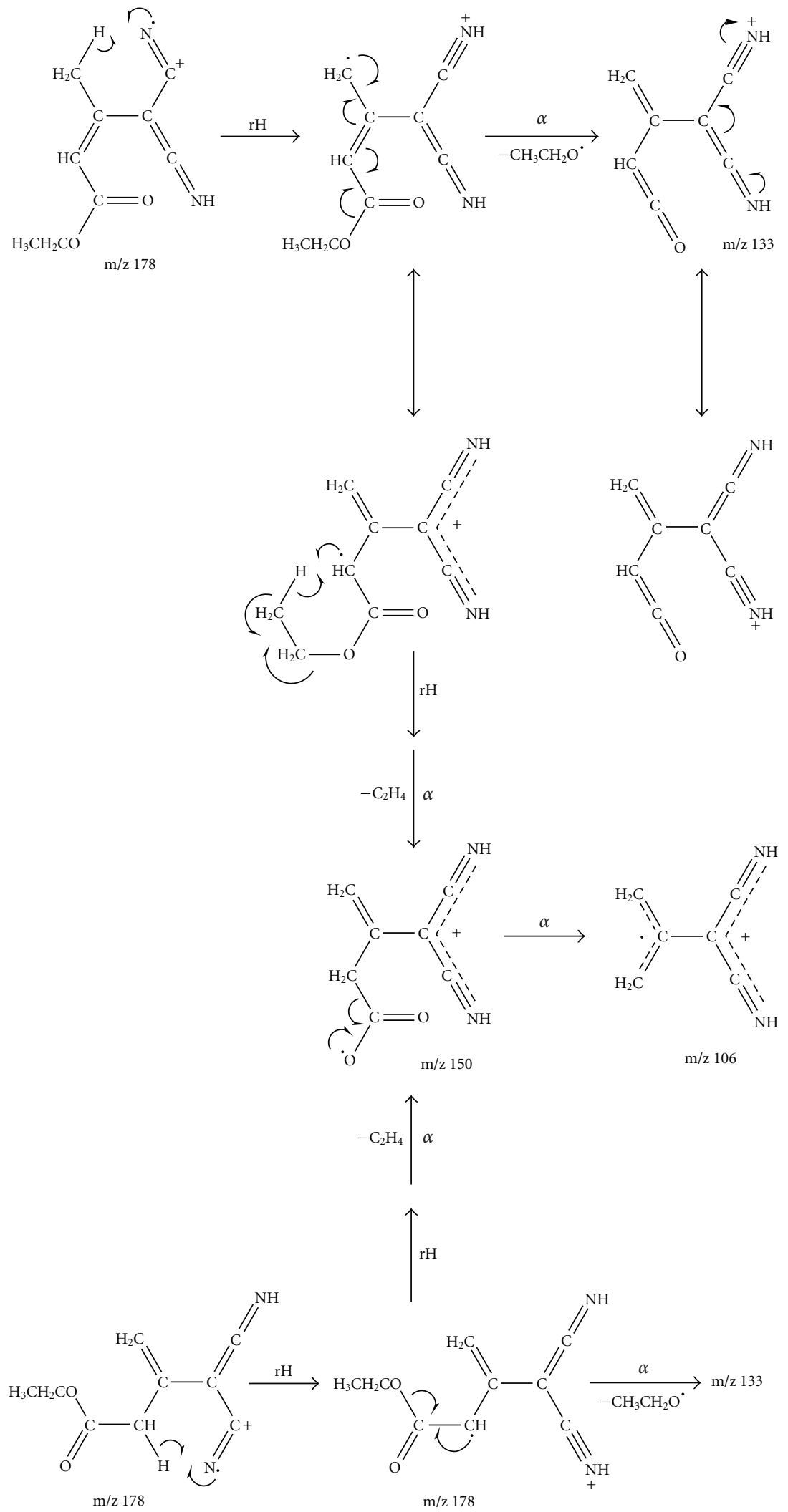

(b)

Scheme 3: Continued. 

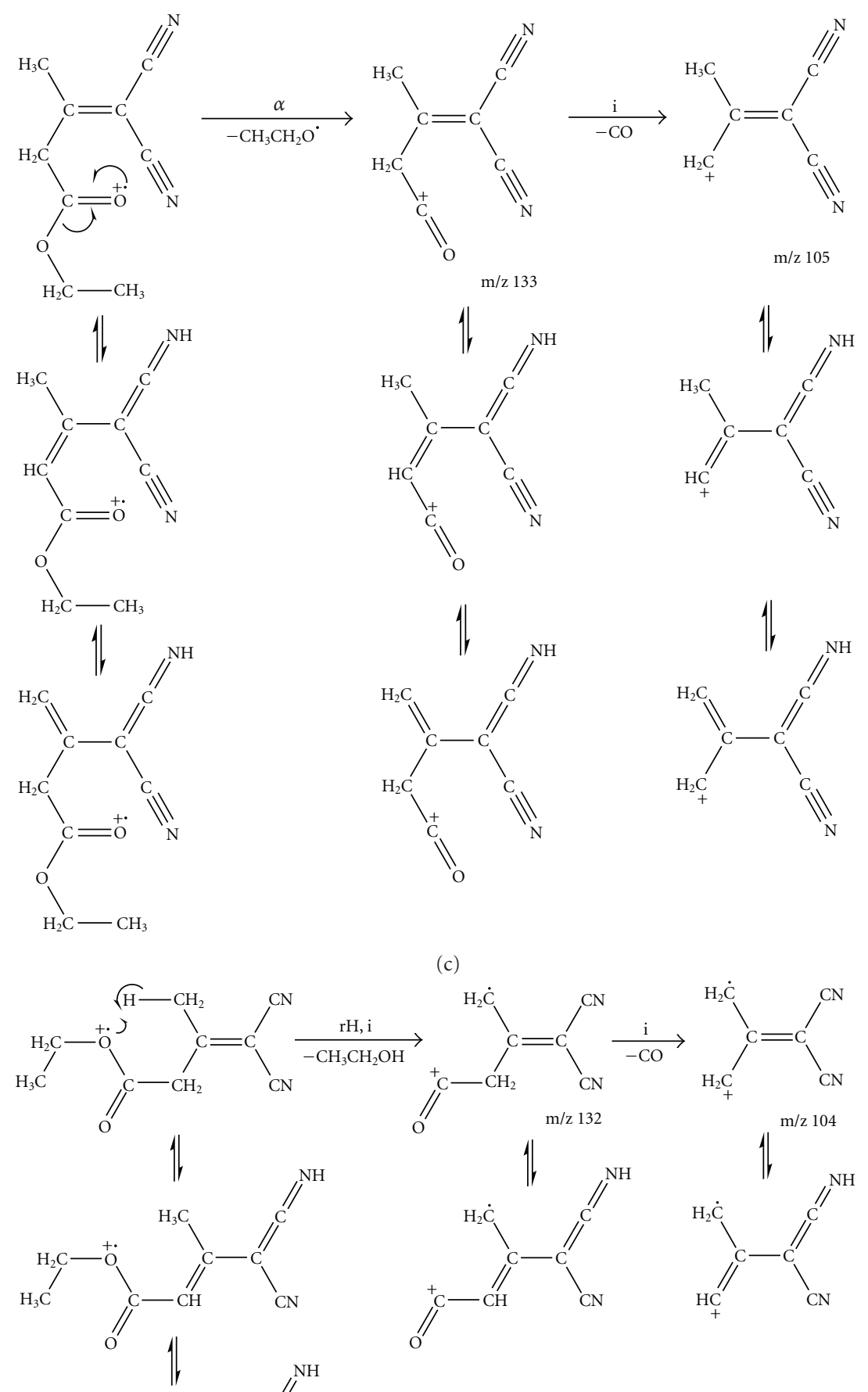<smiles>CC=C(CC(=O)OCC)C(=N)C=C=N</smiles><smiles>C=C=C(N)CI</smiles><smiles>CCOC(C)=O</smiles>

Scheme 3: Continued. 


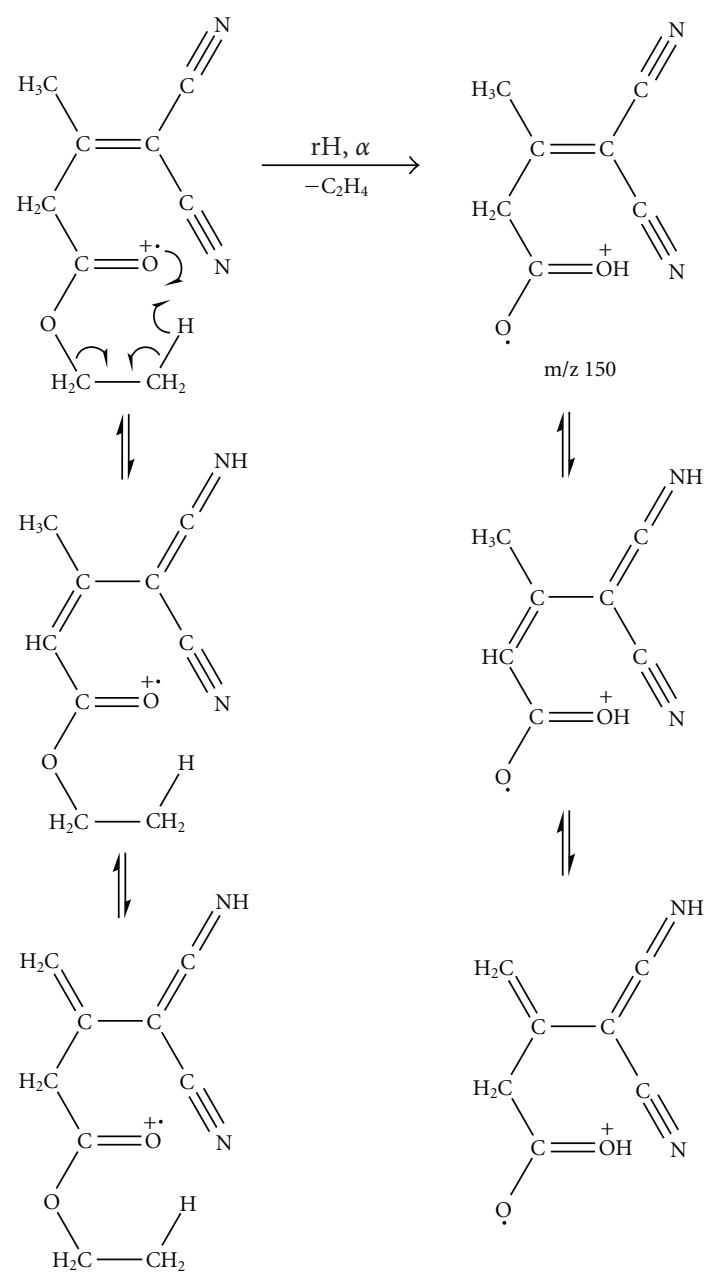

(d)

Scheme 3: Fragment pathways involving both tautomeric forms of ethyl-4,4-dicyano-3-methyl-3-butenoate.

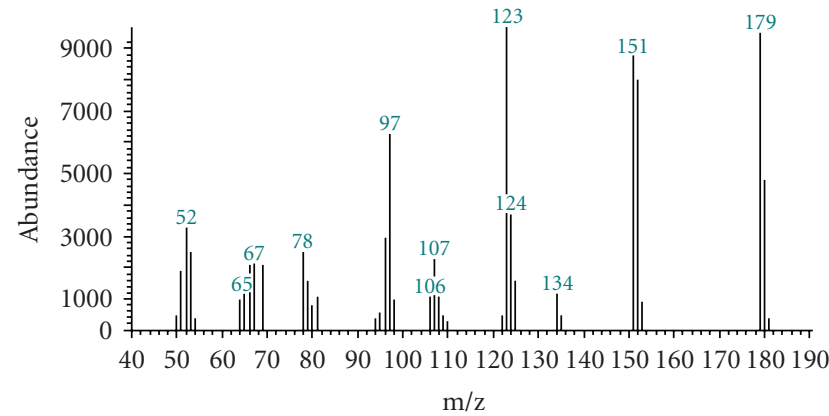

Figure 2: Mass spectrum of diethyl-2-cyano-3-methyl-2pentenodiate.

ion at $\mathrm{m} / \mathrm{z} 106$ comes from that one at $\mathrm{m} / \mathrm{z} 150$; the ion at $\mathrm{m} / \mathrm{z}$ 105 arises from the ion at $\mathrm{m} / \mathrm{z} 133$; the ion at $\mathrm{m} / \mathrm{z} 104$ comes from the ion at $\mathrm{m} / \mathrm{z} 132$; the ions at $\mathrm{m} / \mathrm{z} 66$ and 78 arise from that one at $\mathrm{m} / \mathrm{z} 106$.

Figure 2 shows the mass spectrum of diethyl-2-cyano-3methyl-2-pentenodiate.
TABLE 2: $\mathrm{MS}^{2}$ data for ethyl-4,4-dicyano-3-methyl-3-butenoate.

\begin{tabular}{lc}
\hline Precursor ion $(\mathrm{m} / \mathrm{z})$ & Relevant product ions $(\mathrm{m} / \mathrm{z})$ \\
\hline 178 & $150,133,132,106,105,104,66$ \\
150 & $106,78,66$ \\
133 & 105 \\
132 & 104 \\
106 & 78,66 \\
\hline
\end{tabular}

Scheme 5 shows the main fragment ions that can be generated from all tautomeric structures. Not only the molecular ion but also the ions $\left(\mathrm{M}-\mathrm{C}_{2} \mathrm{H}_{4}\right)^{+}$and $\left(\mathrm{M}-\mathrm{C}_{2} \mathrm{H}_{4}-\right.$ $\left.\mathrm{CO}_{2}\right)^{+}$are not observed. It should be pointed out that the initial hydrogen transfer in Scheme 5(a) can occur to the carbonyl oxygen atom to render the ions at m/z 153 and 152 . In that case the ion at $\mathrm{m} / \mathrm{z} 180$ should be represented as an equilibrium between the protonated ester and the protonated nitrile by hydrogen rearrangement. 


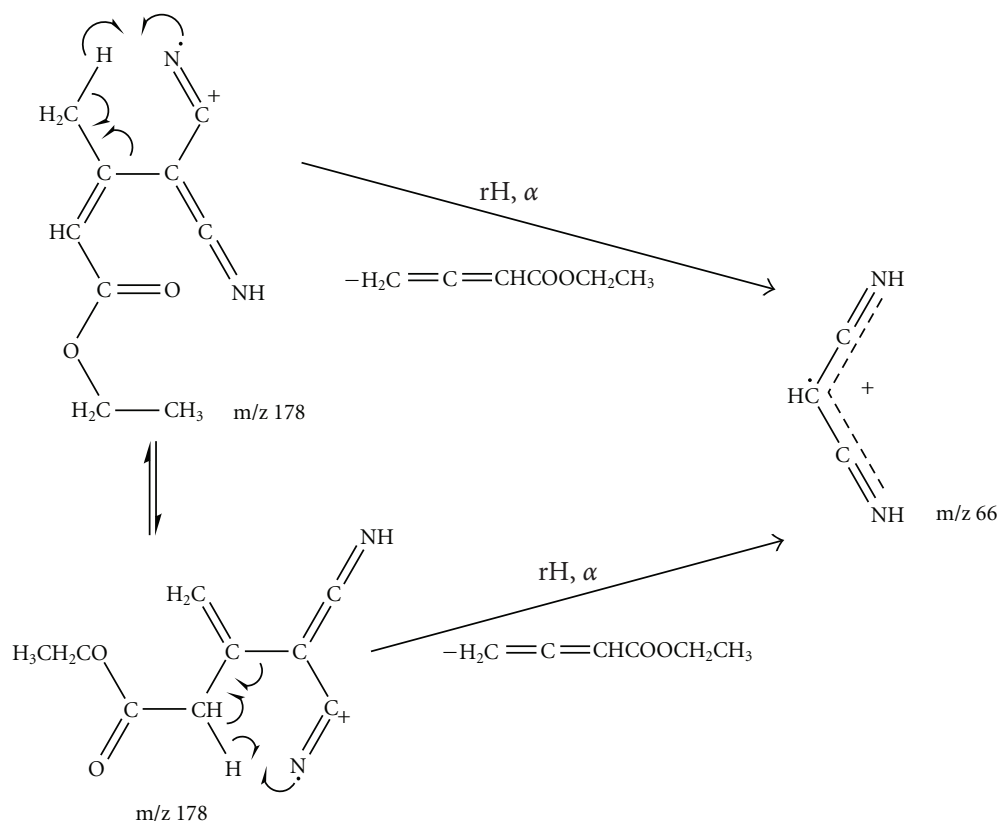

(a)

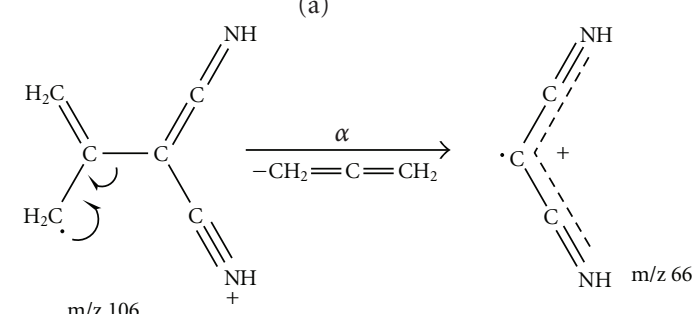

(b)

Scheme 4: Fragmentation pathways involving ketenimine tautomers of ethyl-4,4-dicyano-3-methyl-3-butenoate.

TABLE 3: MS² data for diethyl-2-cyano-3-methyl-2-pentenodiate.

\begin{tabular}{lc}
\hline Precursor ion $(\mathrm{m} / \mathrm{z})$ & Relevant product ions $(\mathrm{m} / \mathrm{z})$ \\
\hline 180 & 152,124 \\
179 & $151,134,123,107,106$ \\
152 & 124 \\
151 & $123,107,106,97,96$ \\
134 & 106 \\
123 & $97,96,79,69$ \\
107 & 79 \\
\hline
\end{tabular}

The ion at $\mathrm{m} / \mathrm{z} 153$ is not significant maybe due to the lower probability of the double hydrogen rearrangement.

The $\mathrm{m} / \mathrm{z} 124$ can be explained from the nitrile form (Scheme 6).

The fragment ion at $\mathrm{m} / \mathrm{z} 67$ can only be explained from the ketenimine form (Scheme 7).

The following fragmentation pathways were confirmed by GC/MS-Ion Trap experiments (Table 3): the ion at $\mathrm{m} / \mathrm{z}$ 152 comes from that one at m/z 180 and the ion at m/z 124 from that one at $\mathrm{m} / \mathrm{z} \mathrm{152}$; the ions at $\mathrm{m} / \mathrm{z} 134,151$, and $\mathrm{m} / \mathrm{z}$

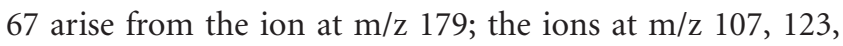
and 106 come from the ion at $\mathrm{m} / \mathrm{z} 151$; the ion at $\mathrm{m} / \mathrm{z} 106$ also arises from the ion at $\mathrm{m} / \mathrm{z} \mathrm{134}$; the ion at $\mathrm{m} / \mathrm{z}$ at 79 is generated by the ions at $\mathrm{m} / \mathrm{z} 107$ and 123 ; the ions at $\mathrm{m} / \mathrm{z} 69$, 96 , and 97 arise from that one at $\mathrm{m} / \mathrm{z} 123$.

In order to better support the specificity of the proposed fragmentation pathways, isotopic exchange with methanol$\mathrm{d}_{1}$ was carried out for the ethyl-4,4-dicyano-3-methyl-3butenoate. The corresponding mass spectrum is shown in Figure 3.

As observed, not only expected shifts are observed $(\mathrm{m} / \mathrm{z}$ 66-67, m/z 78-79, m/z 104-105, m/z 105-106, m/z 106$107, \mathrm{~m} / \mathrm{z}$ 132-133, m/z 133-134, m/z 150-151, m/z 178179) but also $\mathrm{m} / \mathrm{z} 68, \mathrm{~m} / \mathrm{z} 80, \mathrm{~m} / \mathrm{z} 108, \mathrm{~m} / \mathrm{z} 135, \mathrm{~m} / \mathrm{z} 152$, and $\mathrm{m} / \mathrm{z} 180$ are present. This can be explained by taking into consideration the equilibria in Scheme 8. As mentioned before, the enol form from the ester seems to be unable to generate the clusters at m/z 66-68 and m/z 104-108.

To get additional supporting evidence for the occurrence of the ketenimine tautomer that involves the free 

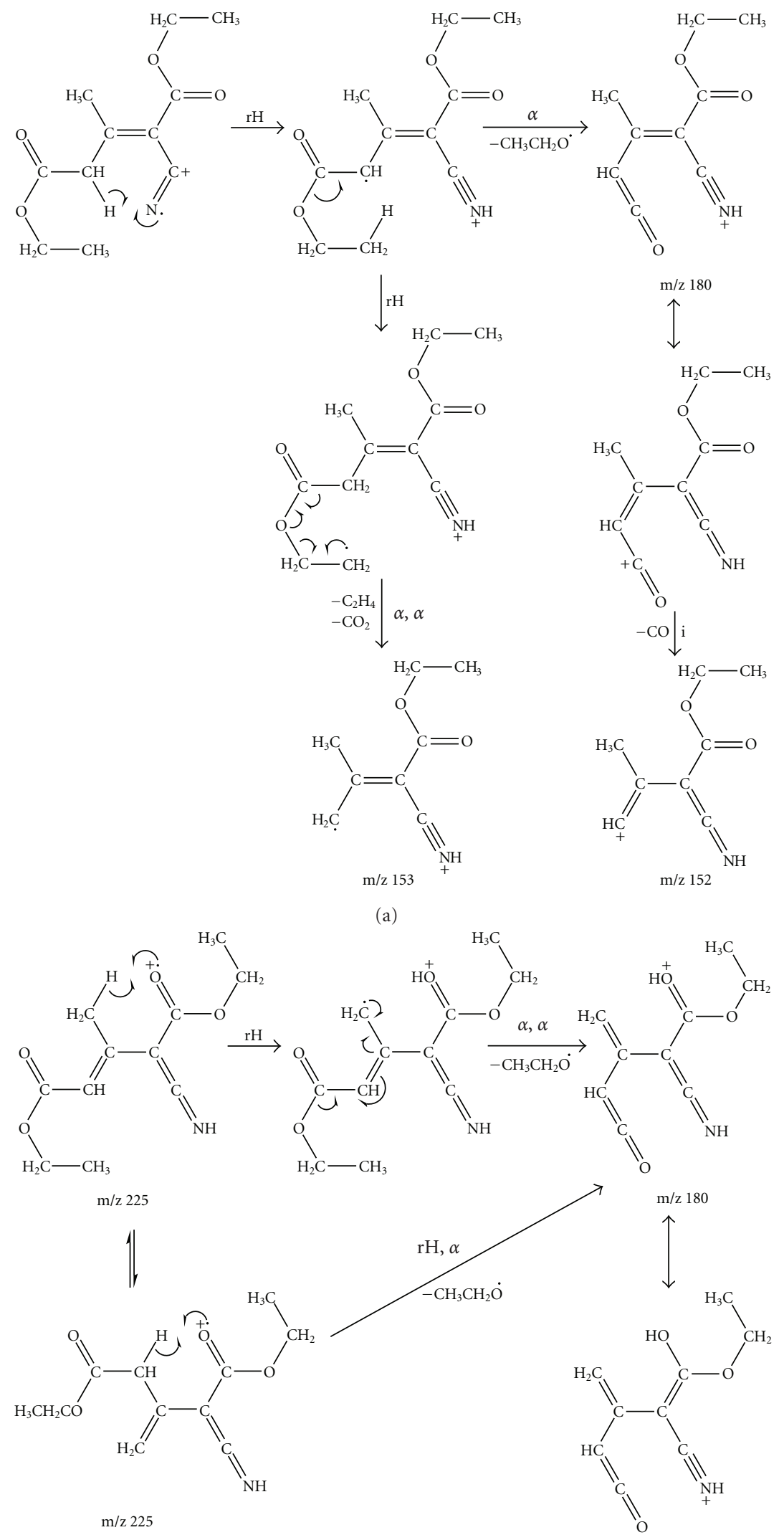

(b)

Scheme 5: Continued. 


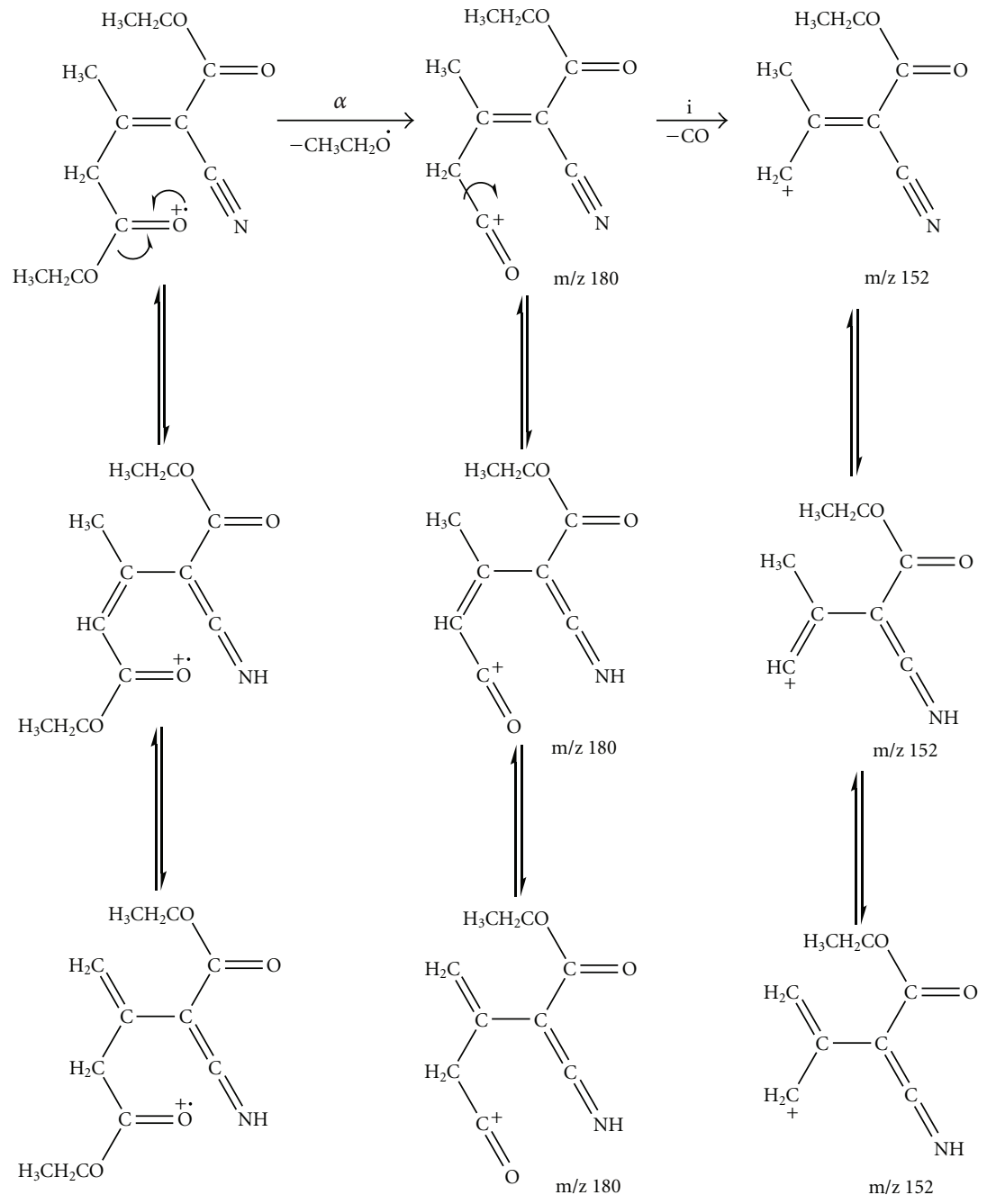

(c)<smiles>CCOC(=O)CC(C)=C(C#N)C(=O)OC</smiles><smiles>CCOC(=O)CC(C)=C(C#N)C=O</smiles><smiles>COC(=O)C/C(C)=C\C#N</smiles>

(d) For the other carbonyl group and for the three tautomers.

Scheme 5: Continued. 


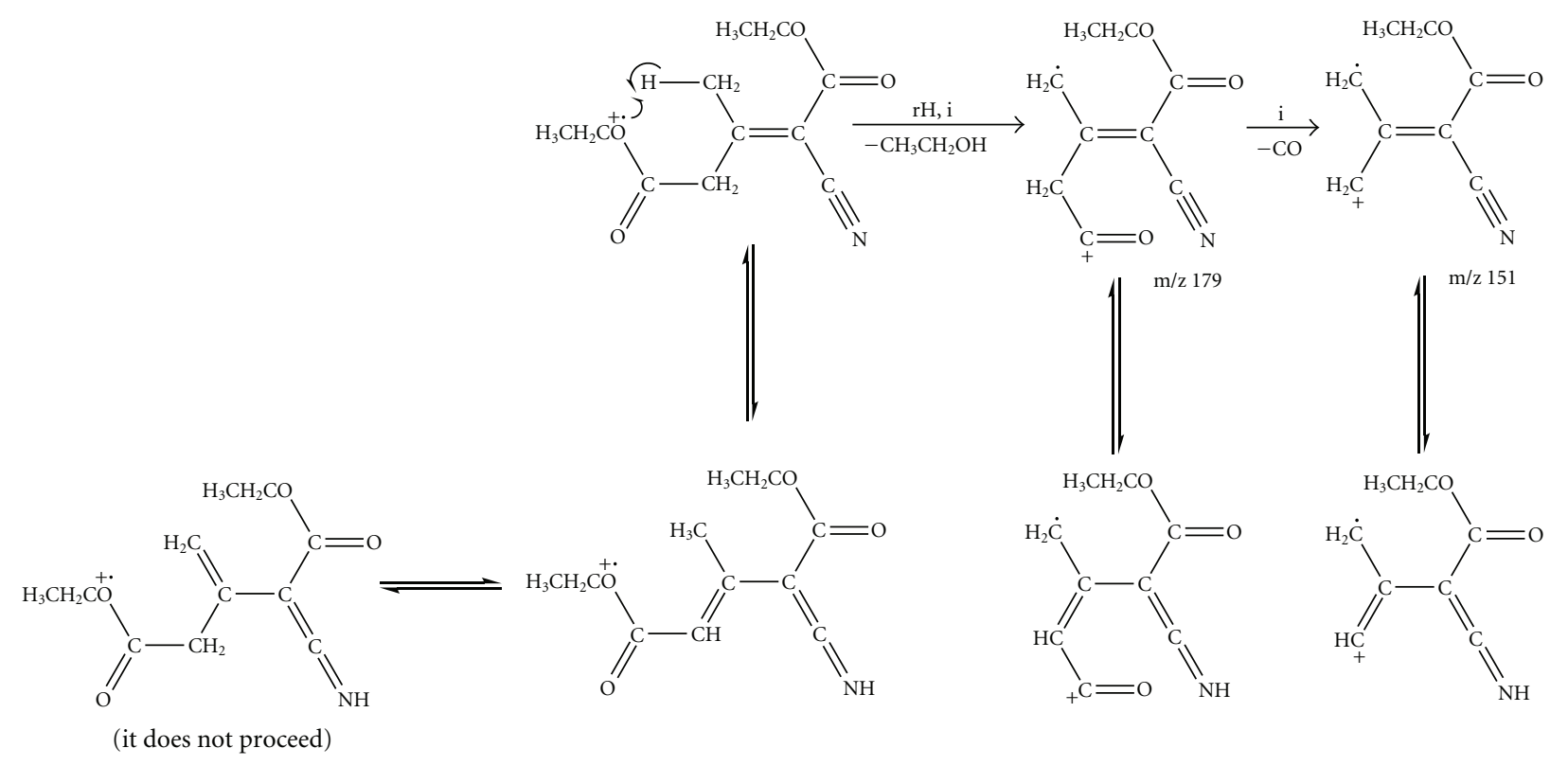

(e)

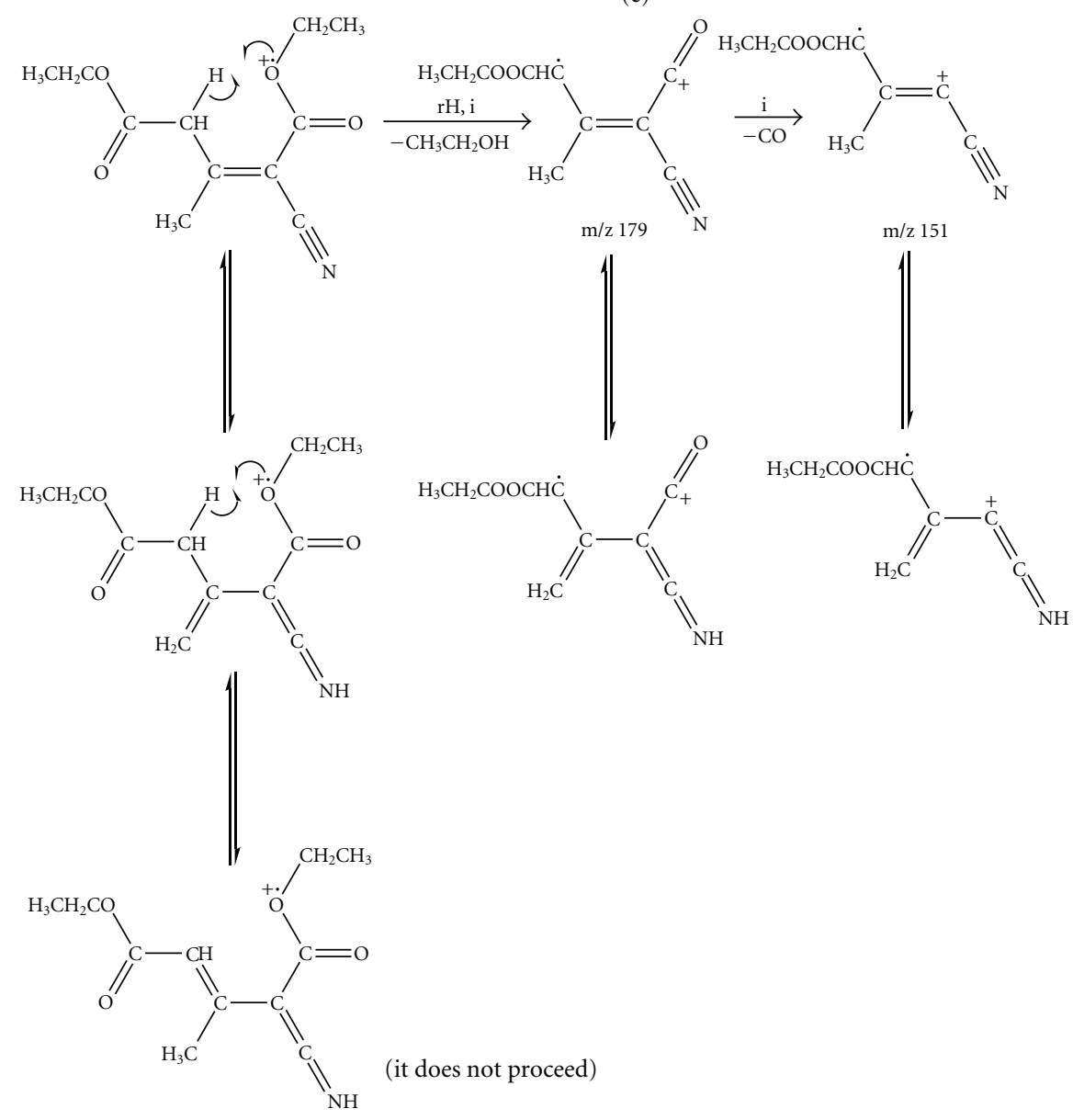

(f) For the other ester moiety.

Scheme 5: Continued. 


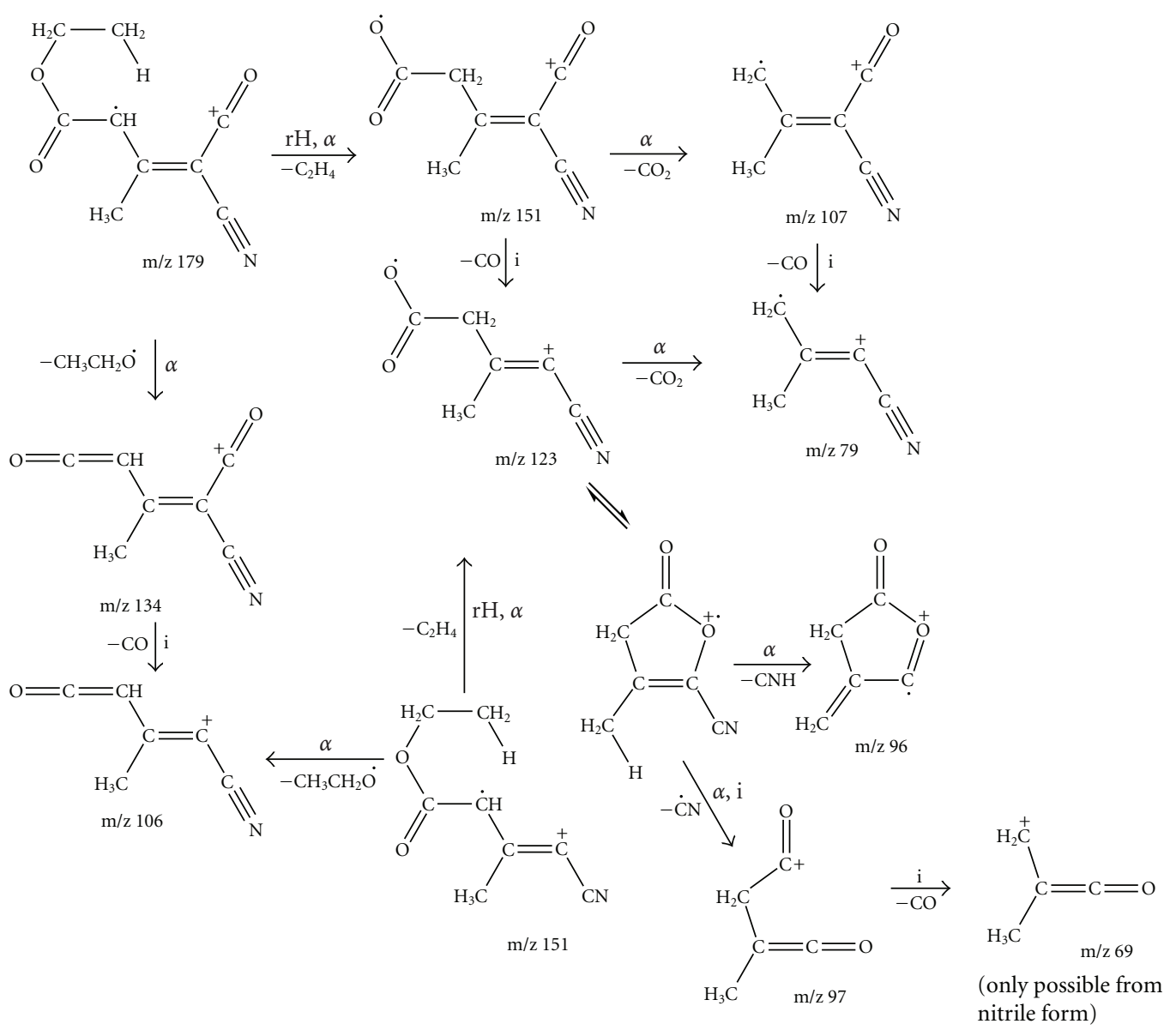

(g)

SCHEME 5: Fragmentation pathways involving all tautomeric structures of diethyl-2-cyano-3-methyl-2-pentenodiate.<smiles>CCOC(=O)CC(C)=C(C#N)C(=[As])OCC</smiles><smiles>CCOC(=O)CC(C)=C(C#N)C#N</smiles><smiles>CCOC(=O)C1CCC=C1C</smiles>

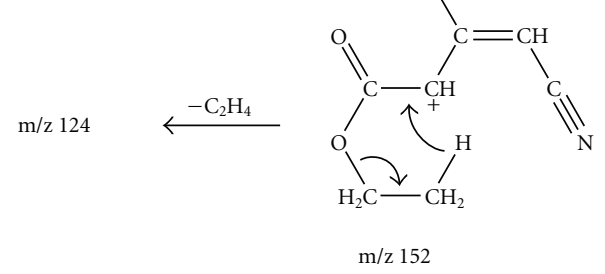

SCHEME 6: Fragmentation pathway involving the nitrile form of diethyl-2-cyano-3-methyl-2-pentenodiate. 


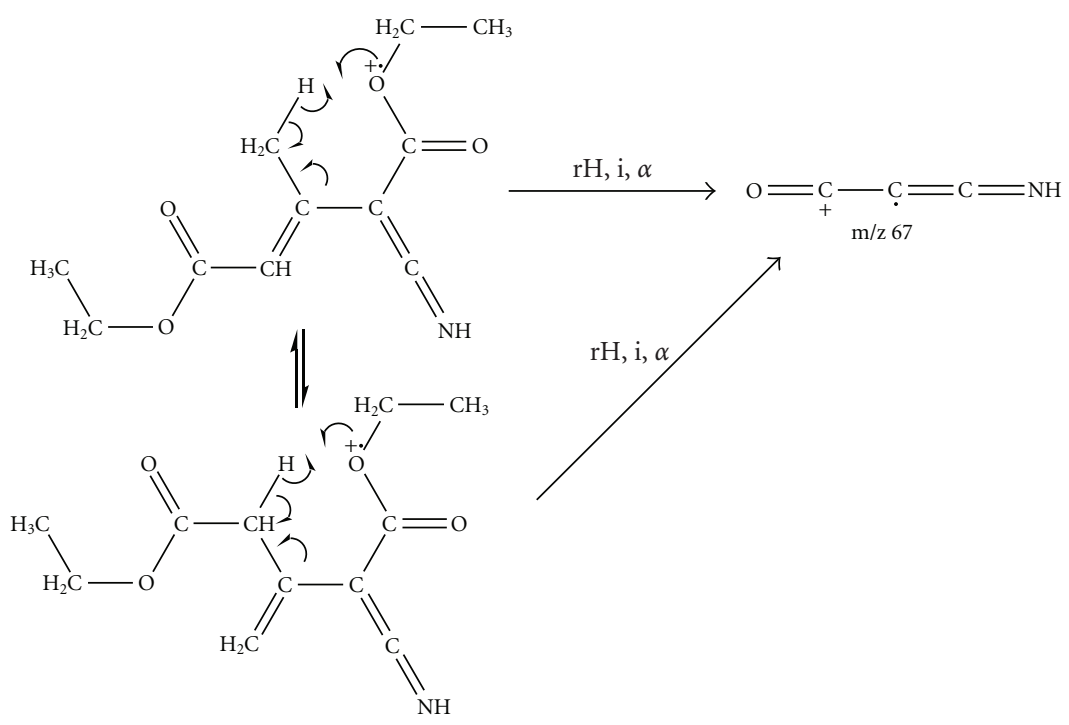

Scheme 7: Fragmentation pathway involving the ketenimine form of diethyl-2-cyano-3-methyl-2-pentenodiate.
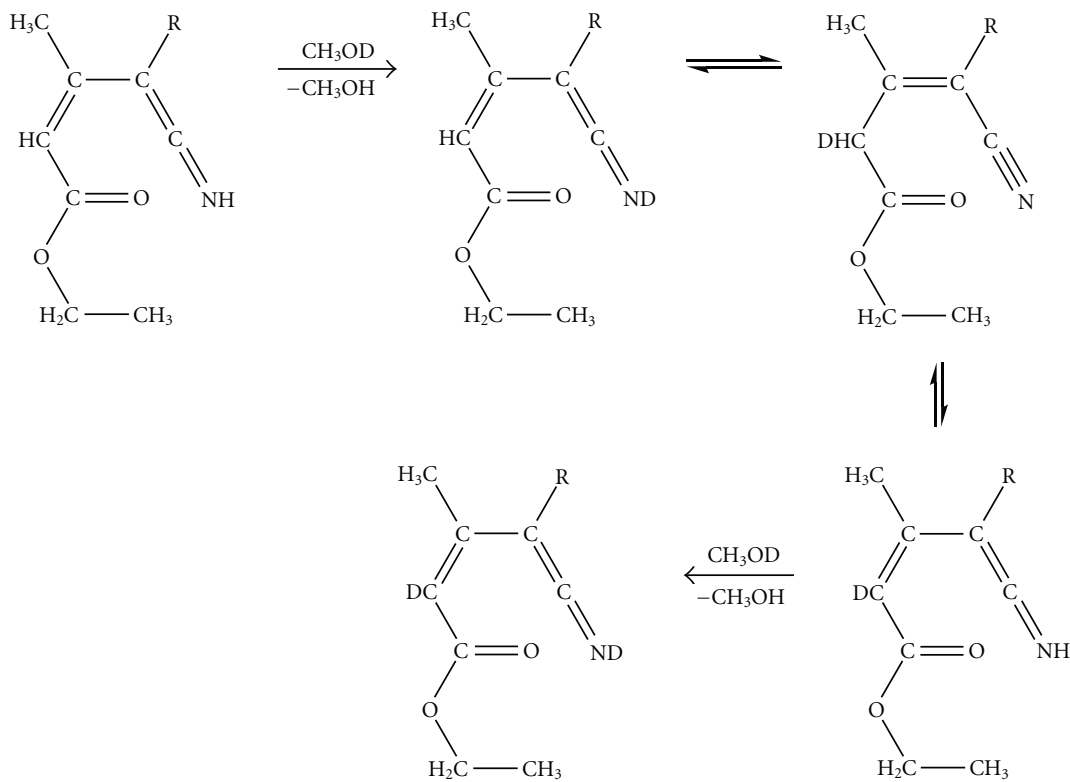

Scheme 8: H/D isotopic exchange for ethyl-4,4-dicyano-3-methyl-3-butenoate ( $\mathrm{R}=$ cyano).

methyl group, the synthesis of ethyl-4,4-dicyano-2,2-diethyl3-methyl-3-butenoate was carried out. This product was analyzed not only by MS (Figure 4) but also by NMR (Table 4) demonstrating that, for this compound, the lack of the methylene group does not preclude tautomerization to the ketenimine form.

The ion at $\mathrm{m} / \mathrm{z} 163$ constitutes the base peak, and it seems to be only explainable from the ketenimine (Scheme 9).

GC/MS-Ion Trap experiments showed that this ion is generated directly from the molecular ion at $\mathrm{m} / \mathrm{z} 234$.

After isotopic exchange with methanol- $\mathrm{d}_{1}$ the fragment ion at $\mathrm{m} / \mathrm{z} 163$ shifts to $\mathrm{m} / \mathrm{z} 164$, that constitutes a supporting evidence for the proponed fragmentation pathway.
Ketenimines react with nucleophiles as amines and alcohols [50], so that the electrophilic addition to the alkene moiety of the ketenimine can be carried out thus obtaining the corresponding amidine, that is possible only if that structure is present (Scheme 10).

Equimolar amounts of ethyl-4,4-dicyano-3-methyl-3butenoate and diethyl amine in diethyl ether were mixed and allowed to react until detection of product formation. After recrystallization the reaction products were identified by ${ }^{1} \mathrm{H}$ and ${ }^{13} \mathrm{C}$ NMR (Table 5). From the corresponding analysis it turns that both ketenimines are present (Scheme 1), that is consistent with mass spectrometric results of the diethylated alkylidene malononinitrile, where the base peak can only 

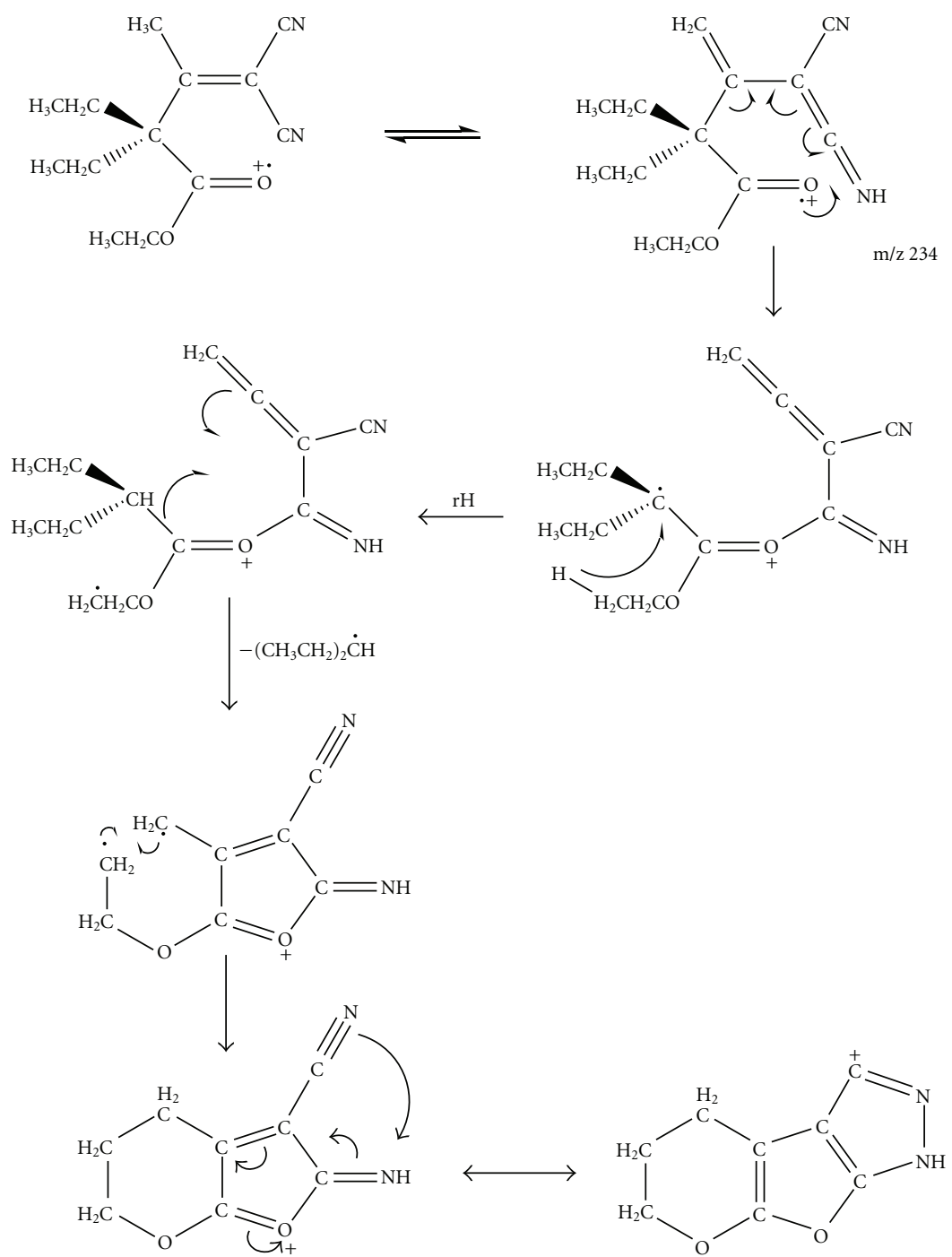

$\mathrm{m} / \mathrm{z} 163$

Scheme 9: Proposed fragmentation pathway involving the ketenimine form of ethyl-4,4-dicyano-2,2-diethyl-3-methyl-3-butenoate.

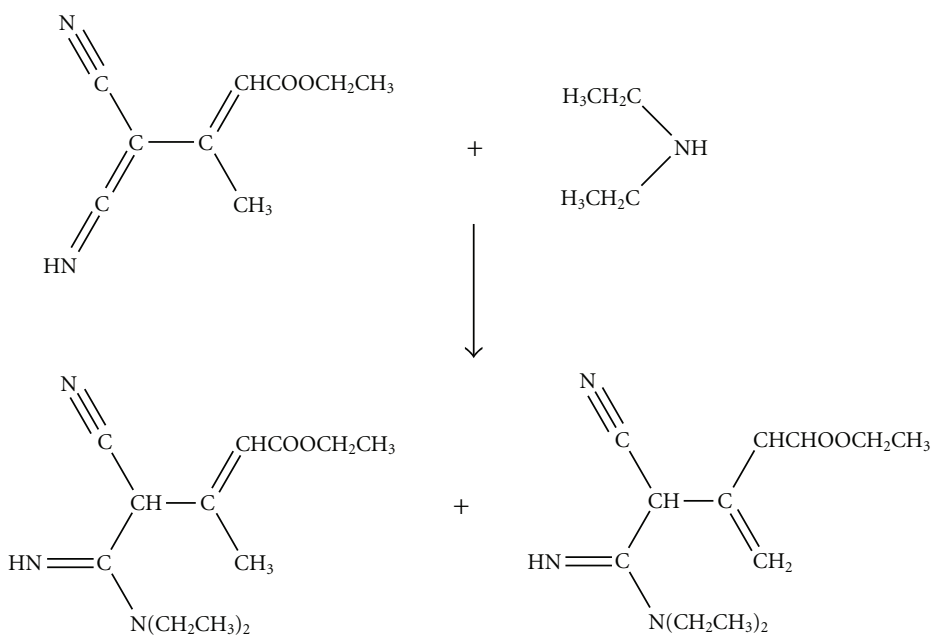

SCHEme 10: Reaction of ethyl-4,4-dicyano-3-methyl-3-butenoate with diethylamine involving the ketenimine Form. 
TABLE 4: Nuclear magnetic resonance spectra $\left({ }^{1} \mathrm{H}\right.$ and $\left.{ }^{13} \mathrm{C}\right)$ of ethyl-4,4-dicyano-2,2-diethyl-3-methyl-3-butenoate.

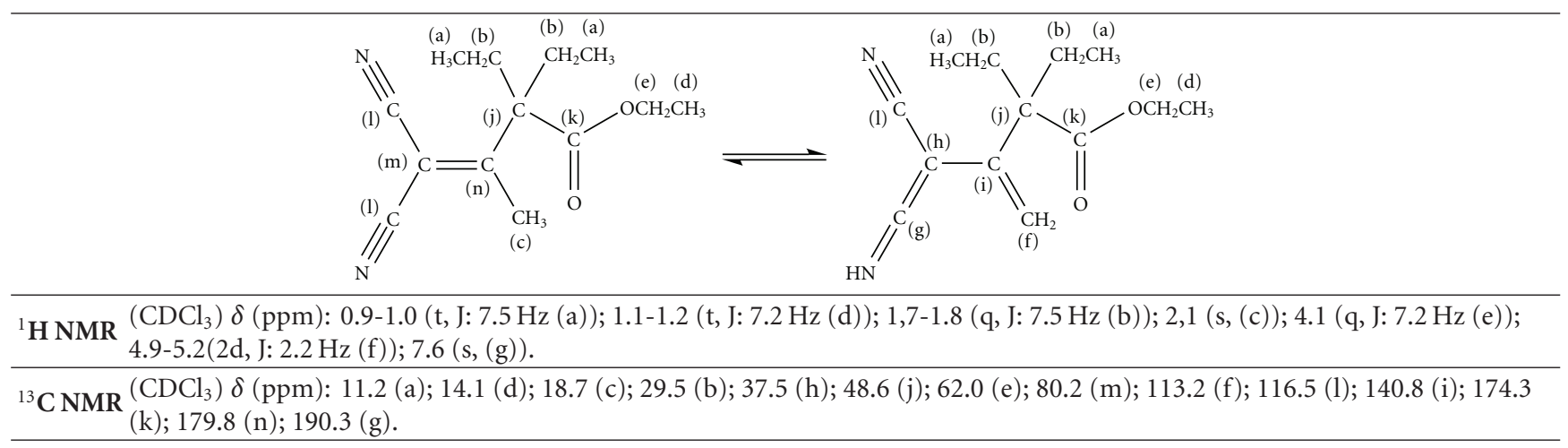

TABLE 5: Nuclear magnetic resonance spectra $\left({ }^{1} \mathrm{H}\right.$ and $\left.{ }^{13} \mathrm{C}\right)$ of the amination products of ethyl-4,4-dicyano-3-methyl-3-butenoate.

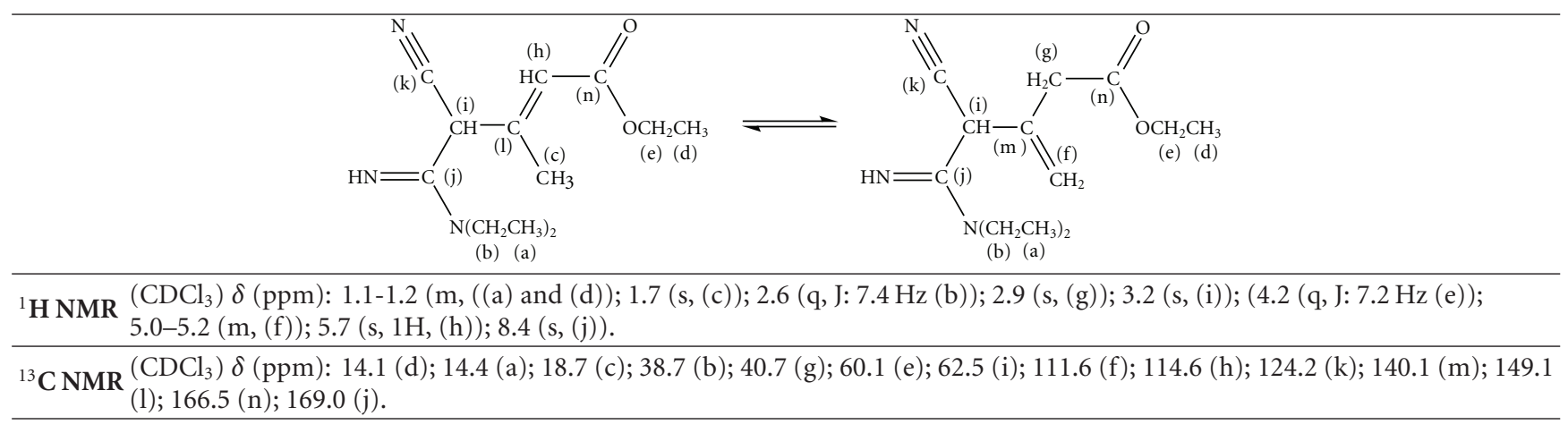

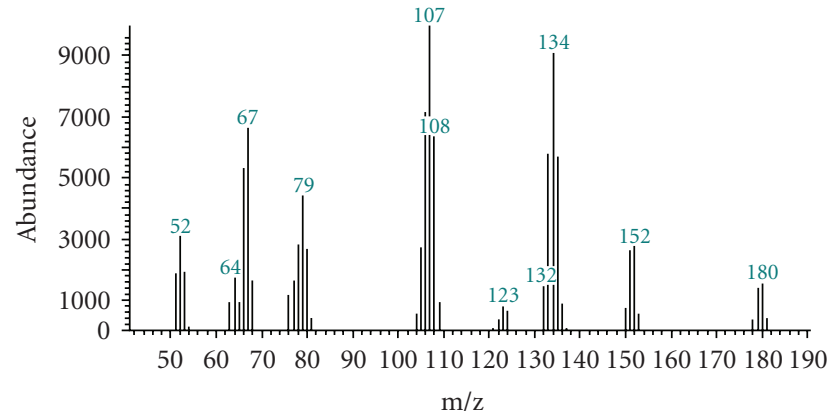

FIGURE 3: Mass spectrum of ethyl-4,4-dicyano-3-methyl-3butenoate after isotopic exchange with methanol- $\mathrm{d}_{1}$.

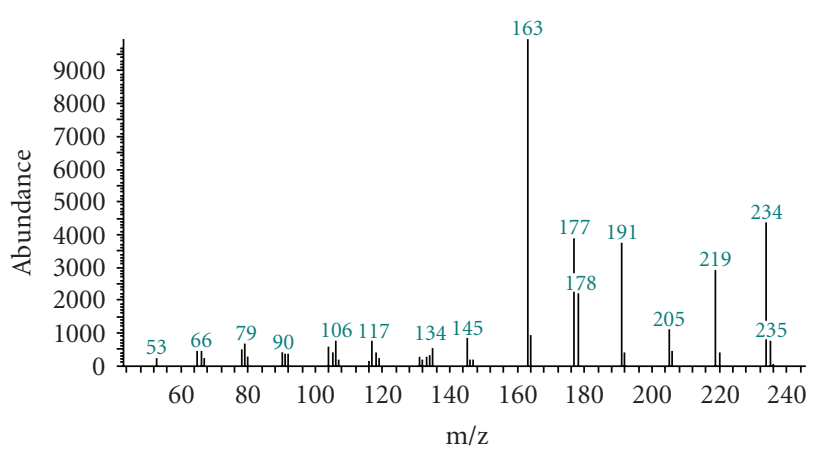

Figure 4: Mass spectrum of ethyl-4,4-dicyano-2,2-diethyl-3methyl-3-butenoate. be justified by the ketenimine involving the methyl group (the ethyl groups on the methylene make impossible the formation of the other ketenimine tautomer).

The bidimensional NMR allowed to confirm the assignments (see experimental part). In addition, the preparation and detection of the amidines from the nitrile in neutral medium is also a strong indication of the presence of the ketenimine structures in the equilibrium.

\section{Conclusions}

The reported evidences found by mass spectrometry in regard to the occurrence of the nitrile-ketenimine tautomerism have been supported through isotopic exchange, $\mathrm{MS}^{2}$ and reactivity experiments (amination reaction and NMR determinations). AM1 calculations were consistent with the relative importance of the ketenimine tautomer for one of the compounds here studied. Although for a long time the value of mass spectrometry as a tool to predict the occurrence of prototropic interconversions in the gas phase has been questioned, nowadays there is enough experimental work that supports this approach. In this sense, there are some key aspects to keep in mind: there should be specific assignments of fragment ions to tautomeric structures, tautomerization is not supposed to proceed between ionic species, and this approach does not intend to constitute a quantitative tool. 


\section{References}

[1] S. Trofimenko, E. L. Little Jr., and H. F. Mower, "Tricyanomethane (cyanoform), carbamyldicyanomethane, and their derivatives," The Journal of Organic Chemistry, vol. 27, no. 2, pp. 433-438, 1962.

[2] T. R. Kasturi, B. N. Mylari, A. Balasubramanian, and C. N. R. Rao, "Spectroscopic studies of keto-enol equilibria: part 2. anomalous ultraviolet absorption spectra of saturated 1,2dicyano esters," Canadian Journal of Chemistry, vol. 40, no. 12, pp. 2272-2277, 1962.

[3] T. R. Kasturi, V. K. Sharma, A. Srinivasan, and G. Subrahmanyam, "Nitrile ketenimine tautomerism in substituted alkylidene malononitriles and alkylidene cyanoacetates: a characteristic UV absorption band," Tetrahedron, vol. 29, pp. 4103-4109, 1973.

[4] J. L. van der Baan and F. Bickelhaupt, "Anion formation versus nitrile ketenimine tautomerism in alkylidene malononitriles and cyanoacetates," Tetrahedron, vol. 31, no. 13-14, pp. 15451548, 1975.

[5] P. Froyen, "The reaction between Phosphonium Ylides and Isocyanates, a convenient route to ketenimines," Acta Chemica Scandinavica. Series B, vol. 28, p. 586, 1974.

[6] T. B. Poulsen, C. Alemparte, and K. A. Jørgensen, "Enantioselective organocatalytic allylic amination," Journal of the American Chemical Society, vol. 127, no. 33, pp. 11614-11615, 2005.

[7] H. Rüterjans, E. Kaun, W. E. Hull, and H. H. Limbach, "Evidence for tautomerism in nucleic acid base pairs. $1 \mathrm{H} \mathrm{NMR}$ study of 15N labeled tRNA," Nucleic Acids Research, vol. 10, no. 21, pp. 7027-7039, 1982.

[8] H. H. Limbach, J. Hennig, R. Kendrick, and C. S. Yannoni, "Proton-transfer kinetics in solids: tautomerism in free base porphines by 15N CPMAS NMR," Journal of the American Chemical Society, vol. 106, no. 14, pp. 4059-4060, 1984.

[9] H.-H. Limbach and B. Wehrle, "Variable temperature $15 \mathrm{~N}$ CPMAS NMR studies of dye tautomerism in crystalline and amorphous environments," Fresenius' Journal of Analytical Chemistry, vol. 327, no. 1, pp. 61-62, 1987.

[10] B. Brzezinski, J. Olejnik, and S. Paszyc, "Fourier transform infrared study on the identification of gossypol tautomers," Journal of Molecular Structure, vol. 239, pp. 23-31, 1990.

[11] F. Aguilar-Parrilla, F. Männle, H. H. Limbach, J. Elguero, and N. Jagerovic, " 15 NMR chemical shifts of NH-pyrazoles in the solid state and in solution at low temperature," Magnetic Resonance in Chemistry, vol. 32, no. 11, pp. 699-702, 1994.

[12] P. E. Hansen, "Hydrogen bonding and tautomerism studied by isotope effects on chemical shifts," Journal of Molecular Structure, vol. 321, no. 1-2, pp. 79-87, 1994.

[13] A. R. Katritzky, I. Ghiviriga, D. C. Oniciu, R. A. More O'Ferrall, and S. M. Walsh, "Study of the enol-enaminone tautomerism of $\alpha$-heterocyclic ketones by deuterium effects on 13C chemical shifts," Journal of the Chemical Society. Perkin Transactions 2, no. 12, pp. 2605-2608, 1997.

[14] S. Bolvig, F. Duus, and P. E. Hansen, "Tautomerism of enolic triacetylmethane, 2-acyl-1,3-cycloalkanediones, 5-acyl Meldrum's acids and 5-acyl-1,3-dimethylbarbituric acids studied by means of deuterium isotope effects on 13C chemical shifts," Magnetic Resonance in Chemistry, vol. 36, no. 5, pp. 315-324, 1998.

[15] J. Elguero, A. R. Katritzky, and O. V. Denisko, "Prototropic tautomerism of heterocycles: heteroaromatic tautomerismgeneral overview and methodology," Advances in Heterocyclic Chemistry, vol. 76, pp. 1-84, 2000.
[16] W. Friedrichsen, T. Traulsen, J. Elguero, and A. R. Katritzky, "Tautomerism of heterocycles: five-membered rings with one heteroatom," Advances in Heterocyclic Chemistry, vol. 76, pp. 85-156, 2000.

[17] V. I. Minkin, A. D. Garnovskii, J. Elguero, A. R. Katritzky, and O. V. Denisko, "The tautomerism of heterocycles: fivemembered rings with two or more heteroatoms," Advances in Heterocyclic Chemistry, vol. 76, pp. 157-323, 2000.

[18] R. M. Claramunt, J. Elguero, and A. R. Katritzky, "Tautomerism involving other than five- and six-membered rings," Advances in Heterocyclic Chemistry, vol. 77, pp. 1-50, 2000.

[19] I. Shcherbakova, J. Elguero, and A. R. Katritzky, "Tautomerism of heterocycles: condensed five-six, five-five, and six-six ring systems with heteroatoms in both rings," Advances in Heterocyclic Chemistry, vol. 77, pp. 51-113, 2000.

[20] H. Komber, H.-H. Limbach, F. Böhme, and C. Kunert, "NMR studies of the tautomerism of cyclo-tris(4-R-2,6pyridylformamidine) in solution and in the solid state," Journal of the American Chemical Society, vol. 124, no. 40, pp. 11955-11963, 2002.

[21] P. Przybylski, M. Włodarz, B. Brzezinski, and F. Bartl, "Spectroscopic studies and PM5 semiempirical calculations of tautomeric forms of gossypol schiff base with (R)tetrahydrofurfurylamine," Journal of Molecular Structure, vol. 691, no. 1-3, pp. 227-234, 2004.

[22] S. Sharif, G. S. Denisov, M. D. Toney, and H.-H. Limbach, "NMR studies of solvent-assisted proton transfer in a biologically relevant Schiff base: toward a distinction of geometric and equilibrium H-bond isotope effects," Journal of the American Chemical Society, vol. 128, no. 10, pp. 3375-3387, 2006.

[23] F. C. V. Larson, S. O. Lawesson, J. Moller, and G. Schroll, "Mass spectra of thioamides," Acta Chemica Scandinavica, vol. 27, pp. 747-755, 1973.

[24] A. Maquestiau and R. Flammang, "Studies of prototropy by mass spectrometric methods," Mass Spectrometry Reviews, vol. 1, no. 3, pp. 237-255, 1982.

[25] M. Masur, H. F. Grustzmacher, H. Münster, and H. Budzikiewicz, "Mass spectrometric fragmentation of the tautomers of 1,3-diketones. A gas chromatographic/mass spectrometric study," Organic Mass Spectrometry, vol. 22, no. 8, pp. 493-500, 1987.

[26] V. Orlov, Yu. Rashkes, T. V. Siretskaya, and V. V. Takhistov, Zhurnal Obshchei Khimii, vol. 58, p. 429, 1988.

[27] A. R. Katritzky, G. Baykut, S. Rachwal, M. Szafran, K. C. Caster, and J. Eyler, "The tautomeric equilibria of thio analogues of nucleic acid bases. Part 1. 2-thiouracil: background, preparation of model compounds, and gas-phase proton affinities," Journal of the Chemical Society, Perkin Transactions 2, no. 10, pp. 1499-1506, 1989.

[28] T. S. Jagodzinski and P. B. Terentév, "Mass spectra of 2thioacylaminothiazoles, 2-thioacylaminobenzothiazoles and their fixed structure amino and imino tautomeric forms," Organic Mass Spectrometry, vol. 24, p. 889, 1989.

[29] V. V. Chistyakov, I. B. Levshin, O. S. Anisimova, Yu. N. Sheinker, and R. G. Glushkov, Doklady Akademii Nauk SSSR, vol. 311, p. 880, 1990.

[30] P. Oksman, G. Stájer, K. Pihlaja, and M. Karelson, "Electron impact ionization mass spectrometry and intramolecular cyclization in 2-substituted pyrimidin-4(3H)-ones," Journal of the American Society for Mass Spectrometry, vol. 5, no. 2, pp. 113-119, 1994. 
[31] M. Galanski, B. K. Keppler, and B. Nuber, "First isolation of an enol of a carboxylic acid by complexation to an (ethane-1,2diamine)-platinum(II) fragment," Angewandte Chemie, vol. 34, no. 10, pp. 1103-1104, 1995.

[32] A. F. Hegarty, J. G. Kelly, and C. M. Relihan, "Formation of hemiaminals by $\mathrm{N}$-protonation of ketenimines (etheneimines) sterically hindered at carbon," Journal of the Chemical Society. Perkin Transactions 2, no. 6, pp. 1175-1181, 1997.

[33] P. B. Terent'ev and A. G. Kalandarishvili, "Application of mass spectrometry for the analysis of organic tautomeric compounds," Mass Spectrometry Reviews, vol. 15, no. 6, pp. 339-363, 1996.

[34] P. E. Allegretti, G. R. Labadie, M. González Sierra, and J. J. P. Furlong, "Mass spectrometric analysis and theoretical calculations of the occurrence of tautomeric structures of hydantoins," Afinidad, vol. 57, no. 485, pp. 42-49, 2000.

[35] P. E. Allegretti, M. M. Schiavoni, H. E. Di Loreto, J. J. P. Furlong, and C. O. Della Védova, "Separation of ketoenol tautomers in $\beta$-ketoesters: a gas chromatography-mass spectrometric study," Journal of Molecular Structure, vol. 560, no. 1-3, pp. 327-335, 2001.

[36] D. Nedeltcheva, B. Damyanova, and S. Popov, "Gas phase tautomerism of tautomeric azo naphthols and related Schiff bases studied by mass spectrometry," Journal of Molecular Structure, vol. 749, no. 1-3, pp. 36-44, 2005.

[37] O. Martiskainen, R. Gawinecki, B. Ośmiałowski, and K. Pihlaja, "Electron ionization mass spectra and tautomerism of 2-phenacylpyridines," European Journal of Mass Spectrometry, vol. 12, no. 1, pp. 25-29, 2006.

[38] P. E. Allegretti, E. A. Castro, and J. J. P. Furlong, "Tautomeric equilibrium of amides and related compounds: theoretical and spectral evidences," Journal of Molecular Structure: THEOCHEM, vol. 499, pp. 121-126, 2000.

[39] P. E. Allegretti, L. Gavernet, E. A. Castro, and J. J. P. Furlong, "Spectrometric and theoretical evidences for the occurrence of tautomeric structures of selected ketones," Journal of Molecular Structure: THEOCHEM, vol. 532, pp. 139-142, 2000.

[40] P. E. Allegretti, A. S. Canepa, R. D. Bravo, E. A. Castro, and J. J. P. Furlong, "Mass spectrometric analysis and theoretical calculations for the occurrence of selected $3(2 \mathrm{H})$ isoquinolinones," Asian Journal of Spectroscopy, vol. 4, p. 133, 2000.

[41] P. E. Allegretti, L. Gavernet, E. A. Castro, and J. J. P. Furlong, "Mass spectral and theoretical studies on the tautomerism of $\beta$-diketones," Asian Journal of Spectroscopy, vol. 5, no. 2, p. 63, 2001.

[42] P. E. Allegretti, C. B. Milazzo, E. A. Castro, and J. J.P. Furlong, "Mass spectrometry as a valuable tool for the study of tautomerism of amides and thioamides," Journal of Molecular Structure: THEOCHEM, vol. 589-590, pp. 161-170, 2002.

[43] P. E. Allegretti, M. S. Cortizo, C. Guzmán, E. A. Castro, and J. J. P. Furlong, "Tautomerism of lactones and related compounds. Mass spectrometric data and theoretical calculations," Arkivoc, vol. 2003, no. 10, pp. 24-31, 2003.

[44] P. E. Allegretti, V. Peroncini, E. A. Castro, and J. J. P. Furlong, "Study of the occurrence of tautomeric forms of ureas and thioureas by mass spectrometry," International Journal for Chemical Science, vol. 1, no. 1, pp. 1-12, 2003.

[45] P. E. Allegretti, D. Asens, M. L. M. De Schiavoni, R. D. Bravo, E. A. Castro, and J. J.P. Furlong, "Mass spectral and theoretical studies on the tautomerism of selectedthioesters," Arkivoc, vol. 2003, no. 15, pp. 134-142, 2003.

[46] P. E. Allegretti, M. L. M. De Schiavoni, M. S. Cortizo, E. A. Castro, and J. J. P. Furlong, "Enol and enethiol occurrence for some ketones and thioketones. Mass spectrometry and theoretical calculations," International Journal of Molecular Sciences, vol. 5, no. 11-12, pp. 294-300, 2004.

[47] P. E. Allegretti, C. B. Milazzo, and J. J. P. Furlong, "Mass spectrometry as a tool for the determination of heats of tautomerization of thioamides in the gas phase," European Journal of Mass Spectrometry, vol. 11, no. 1, pp. 53-63, 2005.

[48] P. E. Allegretti, E. A. Castro, and J. J. P. Furlong, "Mass spectrometry of $\beta$-ketoesters. Some evidence of their tautomerism," European Journal of Mass Spectrometry, vol. 12, no. 5, pp. 317-330, 2006.

[49] P. E. Allegretti, F. Namor, E. A. Castro, and J. J. P. Furlong, "Tautomerism andmass spectra of thiomorpholides," Organic Chemistry: An Indian Journal, vol. 2, pp. 1-13, 2006.

[50] K. Sung, S.-H. Wu, R.-R. Wu, and S.-Y. Sun, "NMR and ab initio studies of amination of ketenimine: direct evidence for a mechanism involving a vinylidenediamine as an intermediate," The Journal of Organic Chemistry, vol. 67, no. 12, pp. 4298-4303, 2002.

[51] A. C. Cope, C. M. Hofmann, C. Wyckoff, and E. Hardenbergh, "Condensation reactions. II. Alkylidene cyanoacetic and malonic esters," Journal of the American Chemical Society, vol. 63, no. 12, pp. 3452-3456, 1941.

[52] C. L. Stevens, R. C. Freeman, and K. Noll, "Nitrogen analogs of ketenes. VII. Reactions with amines," The Journal of Organic Chemistry, vol. 30, no. 11, pp. 3718-3720, 1965.

[53] J. D. White and W. L. Sung, "Alkylation of Hagemann's ester. Preparation of an intermediate for trisporic acid synthesis," The Journal of Organic Chemistry, vol. 39, no. 16, pp. 23232328, 1974.

[54] M. J. S. Dewar, E. G. Zoebisch, E. F. Healy, and J. J. P. Stewart, "AM1: a new general purpose quantum mechanical molecular model," Journal of the American Chemical Society, vol. 107, no. 13, pp. 3902-3909, 1985.

[55] Hyperchem (B) 6.03 for Windows Molecular Modeling System, Hypercube Inc., Gainesville, Fla, USA, 2000. 


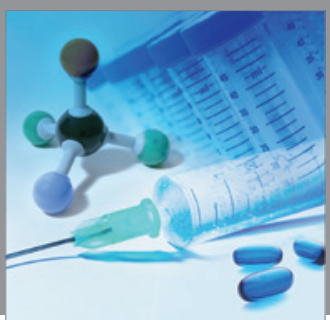

International Journal of

Medicinal Chemistry

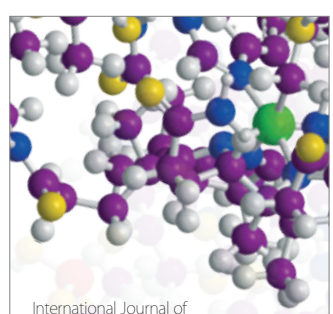

Carbohydrate Chemistry

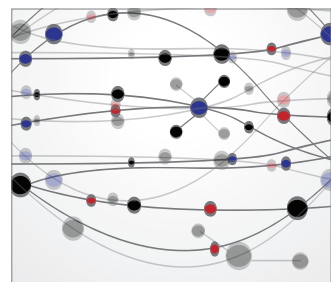

The Scientific World Journal
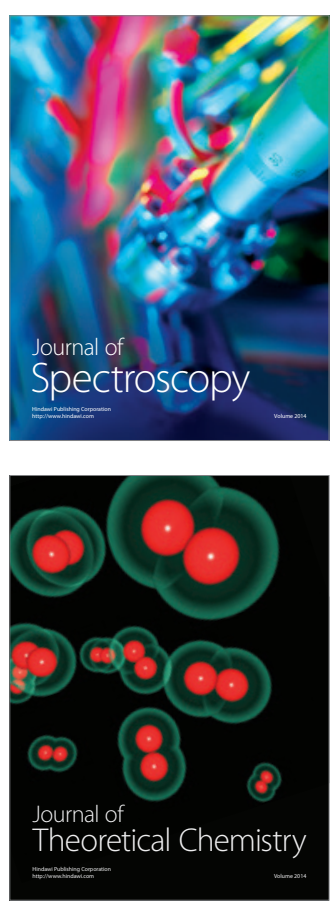
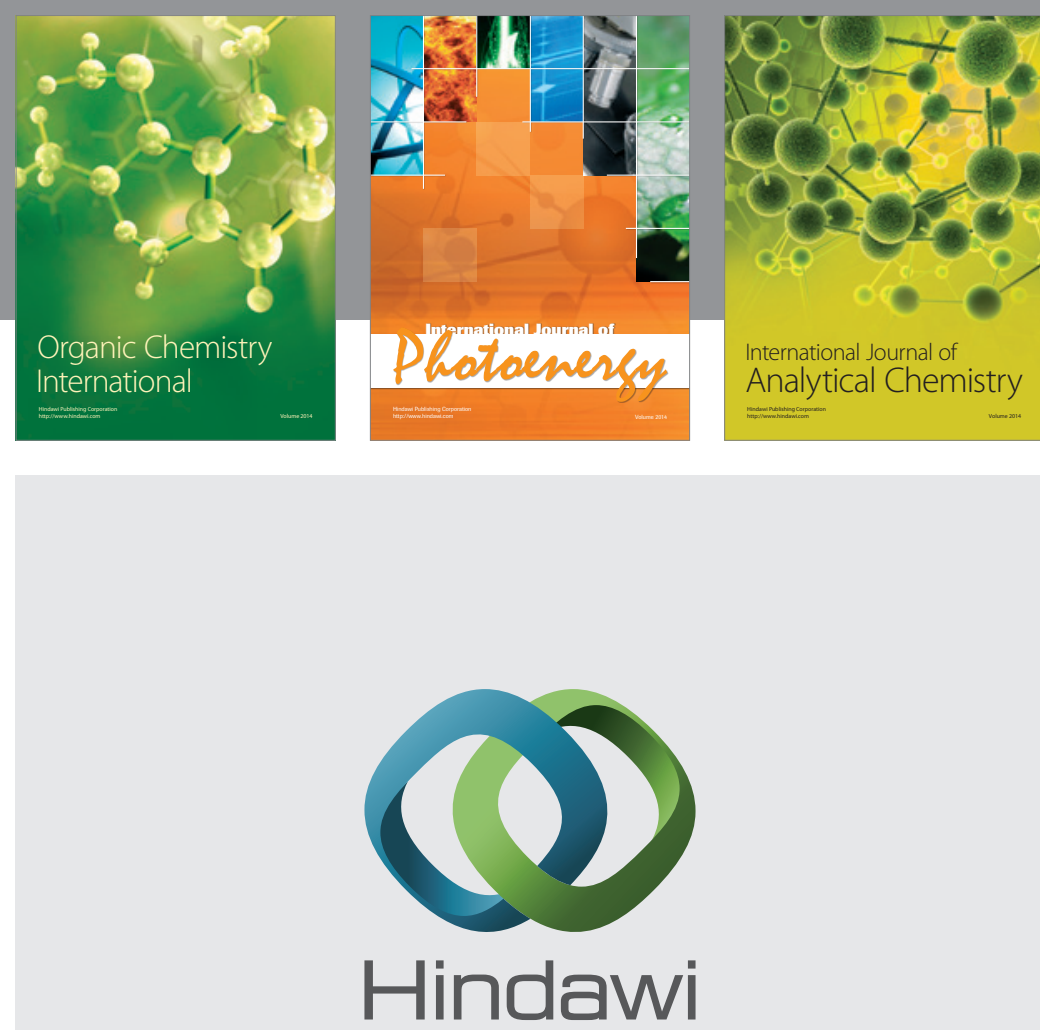

Submit your manuscripts at

http://www.hindawi.com
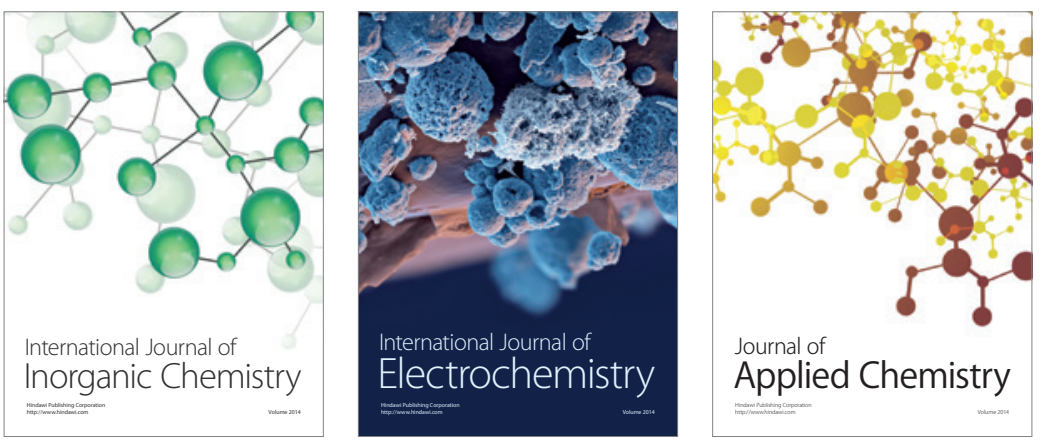

Journal of

Applied Chemistry
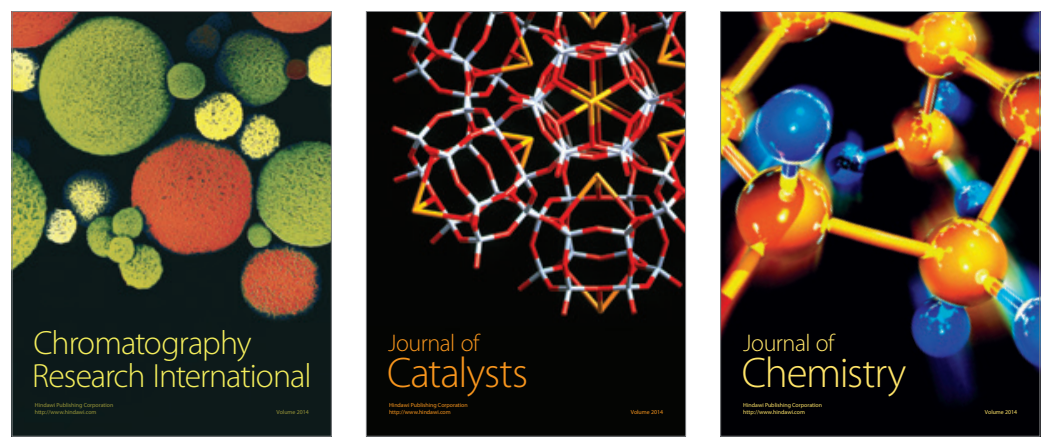
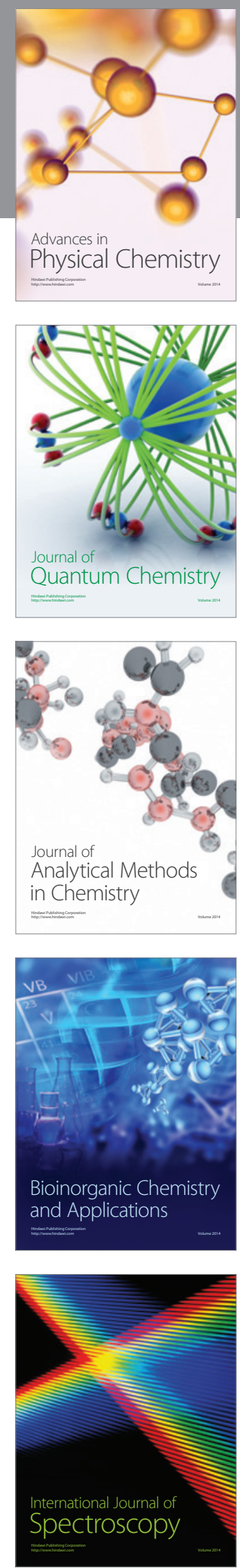